\title{
CHP1-Mediated NHE1 Biosynthetic Maturation Is Required for Purkinje Cell Axon Homeostasis
}

\author{
Ye Liu, ${ }^{1}$ Hans C. Zaun, ${ }^{2}$ John Orlowski, ${ }^{2}$ and Susan L. Ackerman ${ }^{1}$ \\ ${ }^{1}$ Howard Hughes Medical Institute, The Jackson Laboratory, Bar Harbor, Maine 04609, and ${ }^{2}$ Department of Physiology, McGill University, Montreal, \\ Quebec H3G 1Y6, Canada
}

\begin{abstract}
Axon degeneration is a critical pathological feature of many neurodegenerative diseases. Misregulation of local axonal ion homeostasis has been recognized as an important yet understudied mechanism for axon degeneration. Here we report a chemically induced, recessive mouse mutation, vacillator $(\mathrm{vac})$, which causes ataxia and concomitant axon degeneration of cerebellar Purkinje cells. By positional cloning, we identified $v a c$ as a point mutation in the calcineurin-like EF hand protein 1 (Chp1) gene that resulted in the production of mutant CHP1 isoforms with an amino acid substitution in a functional EF-hand domain or a truncation of this motif by aberrant splicing and significantly reduced protein levels. CHP1 has been previously shown to interact with the sodium hydrogen exchanger 1 (NHE1), a major regulator of intracellular $\mathrm{pH}$. We demonstrated that CHP1 assists in the full glycosylation of NHE1 that is necessary for the membrane localization of this transporter and that truncated isoforms of CHP1 were defective in stimulating NHE1 biosynthetic maturation. Consistent with this, membrane localization of NHE1 at axon terminals was greatly reduced in Chp1-deficient Purkinje cells before axon degeneration. Furthermore, genetic ablation of Nhe1 also resulted in Purkinje cell axon degeneration, pinpointing the functional convergence of the two proteins. Our findings clearly demonstrate that the polarized presynaptic localization of NHE/CHP1 is an important feature of neuronal axons and that selective disruption of NHE1-mediated proton homeostasis in axons can lead to degeneration, suggesting that local regulation of $\mathrm{pH}$ is pivotal for axon survival.
\end{abstract}

\section{Introduction}

Axon damage is a prominent pathological hallmark in many human neurodegenerative disorders and often occurs long before the loss of neuronal cell bodies (Medana and Esiri, 2003). In addition, loss of axonal integrity has been linked directly to disease progression (Ferri et al., 2003; Stokin et al., 2005). Despite the significance of axonal degeneration, the causal factors remain poorly understood.

The axonal plasma membrane is enriched with discrete sets of ion channels, pumps, and exchangers that are critical for the transmission of electrical impulses (Waxman et al., 1995). Misregulation of axonal ion gradients, particularly the intraaxonal accumulation of $\mathrm{Ca}^{2+}$ ions via the reverse operation of the $\mathrm{Na}^{+} /$ $\mathrm{Ca}^{2+}$ exchanger, has been suggested to induce axon degeneration in acute injuries such as anoxia and traumatic injury (Stys, 2004).

Received Jan. 28, 2013; revised June 5, 2013; accepted June 24, 2013.

Author contributions:Y.L., J.O., and S.A. designed research; Y.L. and H.C.Z. performed research; Y.L., H.C.Z., J.O., and S.A. analyzed data; Y.L., J.O., and S.A. wrote the paper.

The ReproGenomics program was supported by the National Institutes of Health (Grant\#P01 HD42137). J.0. was supported by a grant from the Canadian Institutes for Health Research (MOP 11221). Services used in this study were supported by CORE Grant \#CA34196 from The Jackson Laboratory. S.L.A. is an investigator of the Howard Hughes Medical Institute. We thank Drs. Mary Ann Handel, John Eppig, and John C. Schimenti of the ReproGenomics Program at The Jackson Laboratory for the vacillator mouse strain, Drs. Zhong-wei Zhang and Hao Wang for advice during the project, Drs. Rob Burgess and Greg Cox for comments on the manuscript, and The Jackson Laboratory sequencing, histology, microinjection, and imaging services for their contributions.

The authors declare no competing financial interests.

Correspondence should be addressed to Susan L. Ackerman, The Jackson Laboratory, 600 Main Street, Bar Harbor, ME 04609. E-mail: susan.ackerman@jax.org.

DOI:10.1523/JNEUROSCI.0406-13.2013

Copyright $\odot 2013$ the authors $\quad 0270-6474 / 13 / 3312656-14 \$ 15.00 / 0$
However, the regulation of protons is also essential because acid is constantly produced as a result of respiration and neuronal electrical activities. Therefore, multiple $\mathrm{pH}$ regulatory mechanisms, including the family of plasma membrane-type $\mathrm{Na}^{+} / \mathrm{H}^{+}$ exchangers, NHE1-NHE5, exist in the brain and especially the nerve terminals (Sánchez-Armass et al., 1994; Chesler, 2003). The NHEs are electroneutral ion exchangers that regulate $\mathrm{pH}$ and cell volume by removing intracellular protons for extracellular sodium ions (Brett et al., 2005; Casey et al., 2010). NHE1-NHE5 exhibit variable cellular localization throughout the brain, and NHE1 (SLC9A1) is the most ubiquitously expressed isoform (Chesler, 2003). Indeed, Nhe1-deficient mice have ataxia, seizures, and selective neuronal death (Cox et al., 1997). However, no axonal defects have been reported in these mice.

The activity of NHEs is regulated by diverse signals and regulatory proteins (Baumgartner et al., 2004). In vitro studies have demonstrated that the $\mathrm{N}$-myristoylated, calcineurin-like $\mathrm{EF}$ hand proteins (CHP1-CHP3) bind to the cytoplasmic $\mathrm{C}$ terminus of NHE1 and activate NHE1 activity (Di Sole et al., 2012). Furthermore, CHP3 promotes biosynthetic maturation and membrane stability of NHE1 (Zaun et al., 2008). Like NHE1, CHP1 is widely expressed, whereas the expression of CHP2 and CHP3 is restricted (Di Sole et al., 2012). Despite the importance of the CHPs, no loss-of-function animal models have been reported and the function of these proteins in the nervous system remains unexplored.

Here we identified a mutant mouse strain, vacillator ( $v a c)$, which displays ataxia concomitant with degeneration of Purkinje cell axons. We discovered that vac is a point mutation in the Chpl 
gene, which causes an amino acid substitution and abnormal splicing, resulting in reduced CHP1 protein levels. Moreover, whereas wild-type CHP1 promotes full glycosylation and thus plasma membrane localization of NHE1, two of the mutant isoforms lack this activity. As a result, NHE1 levels were reduced at a subset of presynaptic terminals in the $C h p 1^{\mathrm{vac} / \mathrm{vac}}$ brain, including those of Purkinje cells. Conversely, ablation of Nhe1 caused a reduction of $\mathrm{CHP} 1$ in these structures, demonstrating the interdependence of NHE1 and CHP1 in membrane localization. Last, we demonstrated that Purkinje cell axon degeneration also occurs in Nhe1 mutant mice, confirming the functional coupling of NHE1 and CHP1 in regulating local $\mathrm{pH}$ at axon terminals.

\section{Materials and Methods}

Immunohistochemistry. Anesthetized mice were fixed by transcardial perfusion with $4 \%$ paraformaldehyde in PBS. Brains were dissected and postfixed in $4 \%$ paraformaldehyde for $2 \mathrm{~h}$ before paraffin embedding. For colorimetric calbindin D-28 staining, Bouin's fixative was used for perfusion and postfixation. For immunofluorescence with most antibodies, antigen retrieval was performed by microwave heating in $0.01 \mathrm{M}$ citrate buffer, $\mathrm{pH}$ 6.0. For immunostaining with anti-CHP1 antibodies, antigen retrieval was performed by incubating sections in a 1:100 dilution of $0.25 \%$ trypsin-EDTA (Invitrogen) in PBS at $37^{\circ} \mathrm{C}$ for $6 \mathrm{~min}$. After antigen retrieval, sections were blocked with $4 \%$ goat serum in PBST $\left(0.02 \%\right.$ Triton in PBS), followed by $4^{\circ} \mathrm{C}$ overnight incubation with primary antibodies. Fluorescent detection was performed with Alexa Fluor488- and Alexa Fluor-555-conjugated secondary antibodies (1:200; Invitrogen). For 3,3'-diaminobenzidine detection of bound calbindin D-28 antibodies, sections were incubated with biotin-conjugated antirabbit IgG antibody (1:100; Sigma) and ExtrAvidin-peroxidase (1:50; Sigma). For all immunohistochemical analyses, at least three mice of each genotype and age were used. Primary antibodies were as follows: rabbit anti-CHP1 (affinity purified, custom-made against recombinant fulllength mouse CHP1 protein; Proteintech), rabbit anti-calbindin D-28 (1:500; Swant), mouse anti-calbindin D-28 (1:500; Sigma), mouse antiglutamate decarboxylase (anti-GAD, 1:300; MBL), mouse anti-PSD95 (1:200; clone L24/18; University of California-Davis/National Institutes of Health NeuroMab Facility), mouse anti-NHE1 (1:100; BD Biosciences), mouse anti-neurofilament medium chain (NFM, 1:300; Invitrogen), and rabbit anti-PKC $\gamma(1: 200 ;$ Abcam).

TEM. Anesthetized mice were fixed by transcardial perfusion with PBS, followed by perfusion with $2 \%$ paraformaldehyde and $2 \%$ glutaraldehyde in cacodylate buffer, $\mathrm{pH}$ 7.2. After overnight postfixation in the same fixative, brains were dissected and processed for transmission electron micrography using standard procedures (Bechtold, 2000). TEM images were collected on a Jeol 1230 microscope.

Mouse strains. The vac mutation was identified in an $\mathrm{N}$-ethyl- $\mathrm{N}$ nitrosourea (ENU)-induced mutagenesis screen at The Jackson Laboratory (Handel et al., 2006). ENU-injected G0 C57BL/6J male mice were crossed to $\mathrm{C} 3 \mathrm{HeB} / \mathrm{FeJ}$ mice to produce G1 founder males. Each G1 founder was crossed to $\mathrm{C} 3 \mathrm{HeB} / \mathrm{FeJ}$ mice to obtain $\mathrm{G} 2$ female mice that were potential mutation carriers. These G2 female mice were backcrossed to the G1 founder to generate homozygous mutant offspring. The vac mutant line was maintained by continued backcrossing of heterozygotes onto C57BL/6J mice for 13 generations (N13). All analyses were performed using $\mathrm{N} 9-\mathrm{N} 13 \mathrm{~B} 6 . \mathrm{Cg}-\mathrm{Ch} p 1^{\text {vac }}$ mice unless otherwise specified. The B6.SJL-Slc9a1 ${ }^{\text {swe }}$ congenic strain was described previously (Cox et al., 1997). Three to five mice (including both males and females) of each genotype were analyzed for each data point. The animal care and use committee of The Jackson Laboratory approved all animal protocols.

Chp $1^{\text {vac }}$ mice were identified by allele-specific PCR, with forward primers chpwtF (5'-GAGGCTGACCAAGATGGTGA-3') or chpmutF (5'-GAGGCTGACCAAGATGGTGG-3') to detect the wild-type or mutant $C h p 1$ allele, respectively. Each forward primer was multiplexed with two common primers: chpint5F (5'-CTTCAAGGCTCTTGGTCTTG$\left.3^{\prime}\right)$ and chpint6R (5'-AACCTTCTCCTCCTATGCAG-3') at a 3:1:4 ratio. Two amplicons were produced for each PCR: a $432 \mathrm{bp}$ product from the allele-specific forward primer and chpint5F and a $527 \mathrm{bp}$ control product from chpint5F and chpint6R.

To generate RP23-222L23 transgenic lines, the C57BL/6J-derived BAC RP23-222L23 was injected into the pronuclei of C57BL/6J zygotes. Three founders were identified by PCR with the primer pair BacT7F, 5'-GCTAATACGACTCACTATAGG-3' , and BACL23T7R, 5' -TGAATC TAAGGCCTTGCAAC- $3^{\prime}$, which recognize the BAC backbone sequence and the $\mathrm{T} 7 \mathrm{end}$ of the inserted genomic fragment, respectively. Founders were crossed to C57BL/6J wild-type $\left(C h p 1^{\mathrm{B} / \mathrm{B}}\right)$ female mice and only line $\mathrm{Tg} 21$ displayed successful germline transmission of the transgene. To obtain Tg21;Chp $1^{\mathrm{vac} / \mathrm{vac}}$ mice, a three-generation breeding scheme was performed. $\mathrm{Tg} 21 ; \mathrm{Chp1}^{\mathrm{B} / \mathrm{B}}$ were first crossed to $\mathrm{C} 3 \mathrm{HeB} / \mathrm{FeJ}$ wild-type $\left(C h p 1^{\mathrm{C} / \mathrm{C}}\right)$ mice and PCR analysis for the BAC transgene were performed to obtain $\mathrm{Tg} 21 ; C_{p} 1^{\mathrm{B} / \mathrm{C}}$ mice. Second, Tg21;Chp1 ${ }^{\mathrm{B} / \mathrm{C}}$ mice were crossed to $C h p 1^{\text {vac/vac }}$ mice and $\mathrm{Tg} 21 ; C h p 1^{\mathrm{C} / \mathrm{vac}}$ offspring were identified with three PCRs with the following primers: the BacT7F and BACL23T7R primers for the BAC transgene; the chpmutF, chpint5F, and chpint6R primer triplex for the $C h p 1^{\text {vac }}$ allele; and the microsatellite marker D2MIT397, which cosegregates with the Chp 1 locus and is polymorphic between the $\mathrm{C} 57 \mathrm{BL} / 6 \mathrm{~J}$ and $\mathrm{C} 3 \mathrm{HeB} / \mathrm{FeJ}$ strains, to distinguish the $\mathrm{Chp} 1^{B}$ and $C h p 1^{\mathrm{C}}$ alleles. Finally, Tg21;Chp $1^{\mathrm{C} / \mathrm{vac}}$ mice were crossed to $C h p 1^{\mathrm{vac} / \mathrm{vac}}$ mice to produce $\mathrm{Tg} 21 ; C h p 1^{\mathrm{vac} / \mathrm{vac}}$ mice.

Genomic mapping. Homozygous vac mice were crossed to BALB/cByJ mice and F1 heterozygotes were intercrossed to generate F2 mice. Genome scans were performed with polymorphic microsatellite markers using genomic DNA collected from 15 affected and 15 unaffected F2 mice. For fine mapping, F2 mice were analyzed using polymorphic microsatellite markers (MIT markers) and single nucleotide polymorphisms. To further narrow the critical interval, homozygous vac mice were also crossed with the $\mathrm{C} 3 \mathrm{HeB} / \mathrm{FeJ}$ and $\mathrm{CAST} / \mathrm{EiJ}$ strains to generate F2 mice.

Plasmid construction. RT-PCR products for both wild-type and vac mutant Chp1 were PCR amplified with chpBamHF: 5' -CAAGGATCCC GGAGGAGCTCCCGTCAC-3' and chpb4TAAR:5' -ATGAGCATCCGA TTTCTTCAC- $3^{\prime}$ primers. The resulting PCR products were inserted into the BamHI/EcoRV sites of the mammalian expression vector pCMV-3Tag (Agilent Technologies) in the appropriate reading frame so that the three FLAG epitope was included at the $\mathrm{C}$ terminus of each isoform for immunological detection.

$R T-P C R$. Total RNA was purified from wild-type or $v a c / v a c$ cerebella using TRIzol Reagent (Invitrogen/Life Technologies). First-strand cDNA synthesis was performed with SuperScript III Reverse Transcriptase (Invitrogen/Life Technologies) according to the manufacturer's instructions. Chp1 full-length cDNAs were amplified with a forward primer chpex1F (5'-TTCTGCCGCTGCTGCTTCTG-3') which is located upstream of ATG start codon, and a reverse primer chpex7R (5'CTGGAGGACACAAGTTTCAG-3'), which is downstream of the stop codon. GAPDH PCR was included as an internal control using GAPDH5/6F: 5'-GGAGAAACCTGCCAAGTATG-3'; GAPDH-7/6R: 5' -CATT GTCATACCAGGAAATG-3' primers.

Relative expression levels of mutant vs wild-type Chp1 transcripts were analyzed using real-time, quantitative RT-PCR. All samples within an experiment were reverse transcribed and the resulting cDNAs were diluted 1:2 in nuclease-free water. Triplicate PCRs were performed for each primer pair. PCRs were performed using iQ SYBR green PCR mater mix in an iQ5 iCycler thermal cycler (Bio-Rad). The thermal cycling conditions were $3 \mathrm{~min}$ at $95^{\circ} \mathrm{C}$ and then 40 cycles of $20 \mathrm{~s}$ at $95^{\circ} \mathrm{C}, 30 \mathrm{~s}$ at $59^{\circ} \mathrm{C}$, and $20 \mathrm{~s}$ at $72^{\circ} \mathrm{C}$. The relative quantification in gene expression was calculated using the $2^{\Delta \Delta \mathrm{Ct}}$ method (Livak and Schmittgen, 2001). GAPDH was used as an internal control. To detect all Chpl isoforms, primer pair chpex1F and chpex2/1R: $5^{\prime}$-ATCTGACTGTGGGAAAAG CC- $3^{\prime}$ were used. To detect the correctly spliced form, wild-type and Chp $1^{\text {D168G }}$ transcripts, chpex4/5F: 5'-AGCAACAAGCTGCACTTT GC-3' and chpex6R: 5' -TTCTGTAAAAGATATGGCAC-3' were used.

Cell culture and DNA transfection. Chinese hamster ovary cells devoid of plasma membrane $\mathrm{Na}^{+} / \mathrm{H}^{+}$exchange activity (AP- 1 cells) (Rotin and Grinstein, 1989) were maintained in $\alpha$-MEM containing $10 \%$ fetal bovine serum, 100 units/ml penicillin/streptomycin, and $25 \mathrm{~mm} \mathrm{NaHCO}_{3}$, $\mathrm{pH} 7.4$, at $37^{\circ} \mathrm{C}, 5 \% \mathrm{CO}_{2}$. Transient transfections were performed with 
Lipofectamine 2000 (Invitrogen/Life Technologies) according to the manufacturer's protocol.

Western blotting. Tissues or cells were lysed in RIPA lysis buffer $(25 \mathrm{~mm}$ Tris- $\mathrm{HCl}, \mathrm{pH}$ 8.0, $100 \mathrm{~mm} \mathrm{NaCl}, 1 \mathrm{~mm}$ EDTA, 0.5\% sodium deoxycholate, $0.1 \%$ SDS, $1 \% \mathrm{NP}-40$, supplemented with complete protease inhibitor mixture [Roche]). Protein concentration was determined using the DC Protein Assay (Bio-Rad). Lysates were separated by SDS-PAGE gels and transferred to PVDF membranes (GE Healthcare) using standard techniques. Primary antibodies were detected with either an anti-mouse or anti-rabbit HRP-conjugated secondary antibody (1: 2000; Bio-Rad) and signal was developed using Supersignal West Pico Chemiluminescent Substrate (Pierce). Western blot bands were quantified by densitometry using the gel analysis tool of ImageJ software and normalized to GAPDH. Primary antibodies for Western blots were as follows: mouse anti-FLAG antibody (\#F3165; Sigma), mouse anti-HA (Covance), rabbit anti-CHP1 (1:250), rabbit anti-CHP3 (Tescalcin) (1: 30; Proteintech), mouse anti-NHE1 (1:300), rabbit anti-NHE1 (1:400; \#SAB4200016; Sigma), mouse anti-PMCA (1:500; Abcam), mouse antiSyntaxin-1 (1:500; Sigma), rat anti-Hsp90 (1:200; Stressgen), and rabbit anti-GAPDH (1:2000; Cell Signaling Technology).

Coimmunoprecipitation. AP-1 cells were transiently transfected with individual variants of $\mathrm{CHP}_{3 \mathrm{FLAG}}$ constructs. Cell lysates were collected $24 \mathrm{~h}$ after transfection as described previously (Zaun et al., 2008). Lysates were centrifuged for $20 \mathrm{~min}$ at $4^{\circ} \mathrm{C}$ to pellet cellular debris and supernatants were precleared with $100 \mu \mathrm{l}$ of $50 \%$ protein G-Sepharose slurry (GE Healthcare) in RIPA buffer for $2 \mathrm{~h}$ at $4^{\circ} \mathrm{C}$. The protein G-Sepharose slurry was removed by brief centrifugation and a fraction of each lysate was removed for Western blotting. Rabbit polyclonal antibodies specific to the FLAG epitope were added to the remaining lysates and incubated with gentle rocking overnight at $4^{\circ} \mathrm{C}$. Next, $100 \mu \mathrm{l}$ of the $50 \%$ protein G-Sepharose slurry was added to each tube and incubated for several hours at $4^{\circ} \mathrm{C}$ with gentle rocking, followed by 6 washes in RIPA buffer. Protein conjugates were eluted by SDS sample buffer and incubated for $30 \mathrm{~min}$ at room temperature without boiling to minimize aggregation of the NHE1 proteins. Samples were then subjected to SDS-PAGE and Western blotting.

In vivo coimmunoprecipitation was performed with mouse cerebellar lysate prepared by homogenization in tenfold ice-cold immunoprecipitation buffer ( $50 \mathrm{~mm}$ Tris, pH 7.4, $150 \mathrm{~mm} \mathrm{NaCl}, 1 \% \mathrm{NP}-40,1 \%$ Triton $\mathrm{X}-100)$ supplemented with protease inhibitors. Homogenates were incubated at $4^{\circ} \mathrm{C}$ for $1 \mathrm{~h}$ with gentle agitation, centrifuged at $1000 \times g$ for 10 min to pellet nuclei and cellular debris, and then precleared with Dynabeads protein $\mathrm{G}$ (Invitrogen/Life Technologies) for $30 \mathrm{~min}$ at $4^{\circ} \mathrm{C}$. After removal of beads, a fraction of each lysate was used for Western blotting. The remaining lysates were added to antibody-protein $G$ complexes that were preformed by incubation of beads with either mouse monoclonal antibody to NHE1, rabbit polyclonal antibodies to CHP1, or for controls, normal mouse or rabbit IgG (Santa Cruz Biotechnology) at $4^{\circ} \mathrm{C}$ for $1.5 \mathrm{~h}$. Immunoprecipitation was performed overnight at $4^{\circ} \mathrm{C}$ and protein conjugates were eluted with $4 \times$ lithium dodecyl sulfate sample buffer (Pierce) at $50^{\circ} \mathrm{C}$. Samples were analyzed with SDS-PAGE and Western blotting.

Membrane fractionation. Mouse cerebella were homogenized in a 10fold ice-cold buffer $(0.32 \mathrm{~m}$ sucrose, $10 \mathrm{~mm}$ HEPES-Na, pH 7.4, and protease inhibitors) using 15 strokes of a glass Teflon homogenizer. The homogenate was centrifuged at $1000 \times g$ for $5 \mathrm{~min}$ at $4^{\circ} \mathrm{C}$ to remove the pelleted nuclear fraction (P1). The remaining supernatant (S1) was spun at 20,800 $\times g$ for $30 \mathrm{~min}$ at $4^{\circ} \mathrm{C}$ to yield the soluble cytoplasmic (S2) and membrane (P2) fractions. The P2 pellet was dissolved in RIPA buffer containing 2\% lithium dodecyl sulfate. Equal amounts of protein from each fraction were then subjected to SDS-PAGE and Western blotting analysis.

Statistical analysis. All data are presented as means \pm SEM. The difference between two groups was assessed by Student's $t$ test; $p<0.05$ was considered statistically significant. GraphPad Prism version 6 software was used for two-way ANOVA analysis.

\section{Results}

vac mutation causes ataxia and axonal degeneration of cerebellar Purkinje cells

The vac mutation was identified in an ENU-induced mutagenesis screen for recessive mutations. Mice homozygous for this mutation appeared indistinguishable from their wild-type or heterozygous littermates before 4 weeks of age. However, at 4-5 weeks of age, homozygous mutant mice displayed mild tremors and an ataxic gait that became pronounced by 7 weeks of age. Concomitant with the onset of locomotor abnormalities, vac/vac mice developed extensive axonal dystrophy of cerebellar Purkinje cells, the projections of which constitute the sole output of the cerebellar cortex.

Immunohistochemistry of brain sections from 5-week-old mutant mice using antibodies to the Purkinje cell markers calbindin-D28 or PKC $\gamma$ (Barmack et al., 2000) revealed widespread hypertrophy of Purkinje cell axons (Fig. $1 \mathrm{~A}$ and data not shown). These axons also had many abnormal focal swellings forming varicosities or large spheroids, characteristic hallmarks of degenerating axons (Dusart and Sotelo, 1994). In contrast, axons in the wild-type cerebellum were thin and of uniform caliber (Fig. 1B).

Previous studies have shown that accumulation of neurofilaments is often observed in injured or diseased axons (Petzold, 2005). Indeed, immunofluorescence with an antibody to neurofilament medium chain (NFM) revealed increased staining in both hypertrophic axons and axonal torpedoes in the vac/vac cerebellum, but not in other brain regions (Fig. $1 C-H$ and data not shown). Coimmunofluorescence with antibodies to NFM and calbindin D-28 revealed that axons with increased levels of NFM were also reactive with anti-calbindin D-28 antibodies, demonstrating that axons of Purkinje cells were selectively affected by the vac mutation.

To further illustrate the degeneration of Purkinje cell axons, cerebellar white matter tracts of the vac mutant and wild-type mice were examined by transmission electron microscopy. Electron micrographs showed that axon pathologies, including myelin sheath decompaction and detachment, accumulation of organelles in swollen nerve fibers, and the presence of vacant areas due to degeneration of nerve fibers, were widespread within the white matter of the vac mutant cerebellum, but were completely absent from the same region in the wild-type cerebellum, confirming our immunofluorescence results (Fig. $1 \mathrm{I}, \mathrm{J}$ and data not shown).

The effect of the vac mutation on Purkinje cell survival in aged mice was investigated by calbindin D-28 immunohistochemistry and hematoxylin and eosin staining of cerebella from 7-weekold, 4-month-old, and 10-month-old vac/vac mice (Fig. 2 and data not shown). Despite extensive degeneration of Purkinje cell axons, no loss of these neurons was observed at 7 weeks of age. However, at 4 months of age, Purkinje cell death was apparent in the mutant, but not the heterozygous or wild-type cerebellum. The degeneration of Purkinje neurons was progressive, and by 10 months of age, many Purkinje cells had degenerated, particularly in the rostral region of the $v a c / v a c$ cerebellum.

\section{Early-onset degeneration of mutant Purkinje cell axon collaterals}

To determine the onset of Purkinje cell axonal degeneration, immunofluorescence was performed with antibodies to PKC $\gamma$ on wild-type and vac/vac cerebellar sections taken at daily intervals from postnatal day 8 (P8)-P20. Beginning at P15, abnormally enlarged spheroids with increased PKC $\gamma$ expression were sporadically observed beneath the Purkinje cell layer and within the 

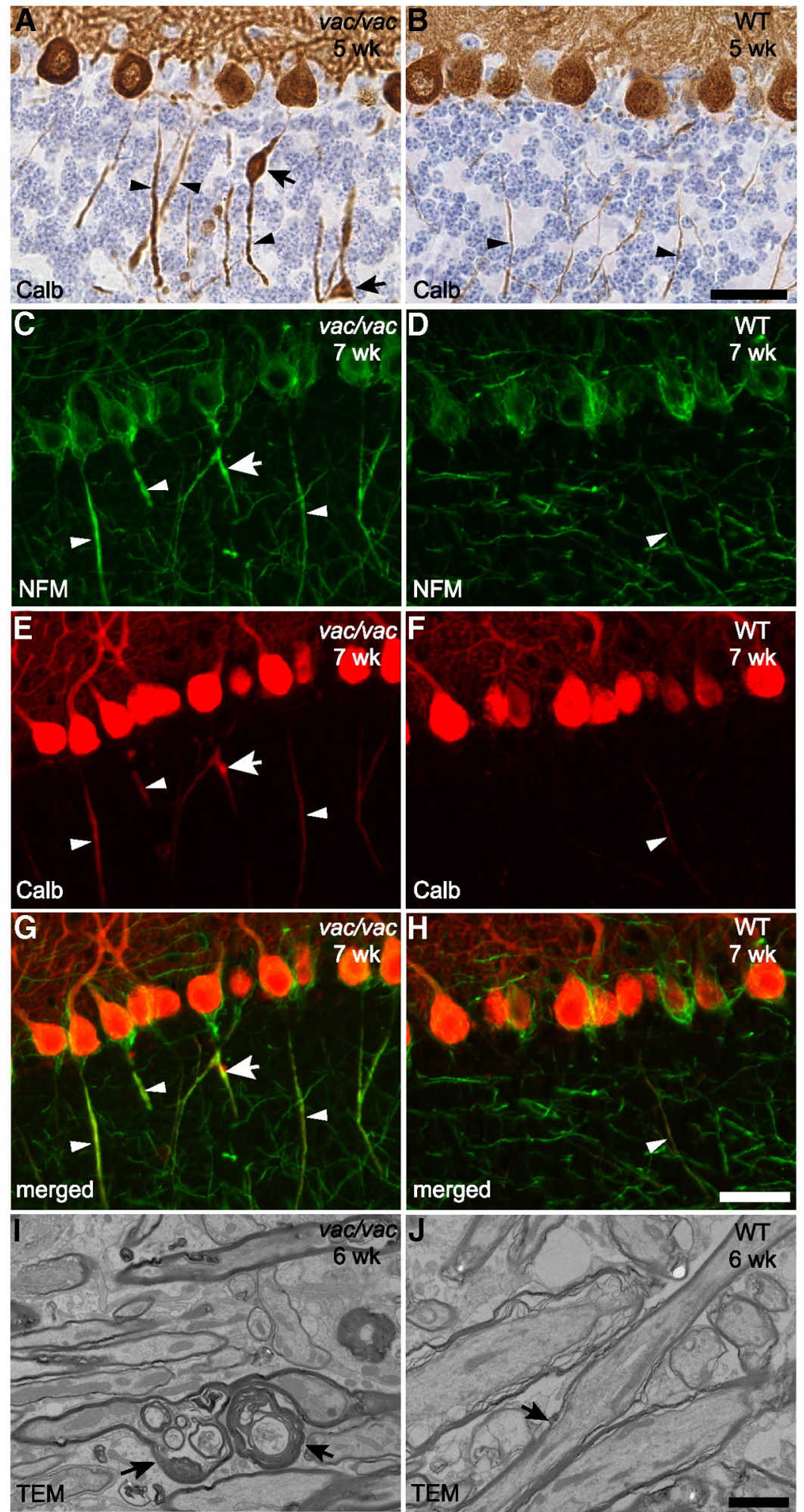

Figure 1. Early-onset axon degeneration of cerebellar Purkinje cells in vac/vac mice. $A, B$, Calbindin D-28 (Calb) immunostaining (brown) of Purkinje cells and their projections in lobule $V$ of the cerebellum from 5-week-old vac/vac $(\boldsymbol{A})$ and wild-type (WT; $\boldsymbol{B})$ mice. Sections were counterstained with hematoxylin. In contrast to WT axons ( $\boldsymbol{B}$, arrowheads), many mutant axons were hypertrophic $(\boldsymbol{A}$, arrowheads) and had local swellings ( $\boldsymbol{A}$, arrows). $\boldsymbol{C}-\boldsymbol{H}$, Representative images of coimmunofluorescence with antibodies to neurofilament subunit NFM $(\boldsymbol{C}, \boldsymbol{D})$, calbindin D-28 $(\boldsymbol{E}, \boldsymbol{F})$, and merged images $(\boldsymbol{G}, \boldsymbol{H})$ showing intraaxonal accumulation of NFM in mutant Purkinje axons in the 7-week-old vac/vac cerebellum $(\boldsymbol{C}, \boldsymbol{E}, \boldsymbol{G})$ compared with that of age-matched WT mice $(\boldsymbol{D}, \boldsymbol{F}, \boldsymbol{H})$. Arrows indicate local axonal swellings in the mutant cerebellum and arrowheads indicate representative Purkinje axons. Camera exposure times were equal for images of the same channel. $\boldsymbol{I}, \boldsymbol{J}$, Representative transmission electron microscope (TEM) images of axons in the 6-week-old vac/vacmutant $(\boldsymbol{I})$ and WT $(\boldsymbol{J})$ white matter in the cerebellar cortex. Arrows in I indicate degenerative axons either cut longitudinally (left) or transversely (right). The arrow in $\boldsymbol{J}$ indicates a representative, longitudinally cut, WT axon. Scale bars: $\boldsymbol{A}, \boldsymbol{B}, 30 \mu \mathrm{m} ; \boldsymbol{C}-\boldsymbol{H}, 40 \mu \mathrm{m} ; \boldsymbol{I}, \boldsymbol{J}, 2 \mu \mathrm{m}$ lower molecular layer. These abnormal structures became more pronounced and widespread by P17 (Fig. 3 and data not shown).

The position of these PKC $\gamma$-positive spheroids suggests they are likely axonal boutons formed by Purkinje cell axon collaterals, which sprout from the axon shafts of Purkinje cells and synapse onto other Purkinje cells (Larramendi and Lemkey-Johnston, 1970). To further investigate the nature of the spheroids, coimmunofluorescence was performed with PKC $\gamma$ antibodies to label structures of Purkinje cells and a GAD antibody to visualize GABAergic axon terminals. Indeed, the PKC $\gamma$-positive spheroids in the mutant cerebellum were also positive for GAD. Furthermore, in contrast to wildtype boutons that were closely juxtaposed to Purkinje cell dendrites, these misshapen boutons were often displaced. These observations demonstrated that degeneration of axon collaterals of $\mathrm{vac} / \mathrm{vac}$ Purkinje cells was an early event in the cerebellar pathogenesis of this mutant strain.

\section{vac mutation disrupts the mouse Chp1 gene}

The vac mutation was initially mapped to chromosome 2 by a genome-wide scan of polymorphic markers on affected F2 mice. Analysis of additional F2 mice further narrowed the critical region to a 0.15 centimorgan interval (1.14 megabases) containing 31 protein-coding genes (Fig. $4 A$ ). We performed RT-PCR analysis of genes within the vac interval using cerebellar cDNAs and discovered aberrant Chp1 (also known as calcineurin B homologous protein 1 or 150003 O03Rik) transcripts in the vac mutant, but not the wild-type cerebellum. Comparison of vac mutant and wild-type genomic DNA revealed an $A$ to $G$ base transition in exon 6 at nucleotide 657 of the Chp1 gene. As a result, an aspartic acid was changed to glycine at codon 168 , which is the $z$ position of the fourth EF hand (EF4) and one of the six residues that are involved in calcium ion binding (Barroso et al., 1996). Furthermore, analysis of mutant Chp1 RTPCR products demonstrated that the A657G mutation created a novel splice donor site. This site, and cryptic splice sites in intron 6, caused the production of two aberrant transcripts: a shorter isoform containing a truncated exon 6 (dltCS) and a longer isoform (dltCL) consisting of the truncated exon 6 and an additional downstream exon. In both the $d l t C S$ and $d l t C L$ transcripts, a frameshift 
occurred after the A657G mutation that caused deletion of the second half of EF4 (Fig. 4B,C). Quantitative real-time RTPCR revealed that the overall expression of all three Chp1 transcripts in the mutant cerebellum was comparable to that of the wild-type transcript, with the correctly spliced missense transcript D168G constituting $\sim 30 \%$ of all mutant Chp1 mRNAs (data not shown).

To determine whether the vac mutation affects $\mathrm{CHP} 1$ protein levels, rabbit polyclonal antibodies were generated with recombinant full-length mouse $\mathrm{CHP} 1$ protein as immunogen. These antibodies detected a single $22 \mathrm{kDa}$ band in Western blots of cerebellar lysates prepared from P7 and 3-month-old wild-type mice. However, in Chp $1^{\text {vac/vac }}$ cerebellar samples, the antibodies recognized two closely migrating bands (Fig. 4D). Based on molecular mass prediction, the fainter, higher molecular weight band likely corresponded to the translation product of the dltCL transcript, whereas the protein products of the dltCS and D168G transcripts likely comigrated in the lower molecular weight band. Interestingly, although the levels of Chp1 mRNAs were not altered in the $C h p 1^{\text {vac/vac }}$ cerebellum, we observed a $70 \%$ reduction of the total levels of CHP1 protein isoforms in both the developing and the adult $C h p 1^{\mathrm{vac} / \mathrm{vac}}$ cerebellum, suggesting that the mutant isoforms have reduced stability compared with the wildtype protein (Fig. 4E).

To confirm that the $C h p 1^{\text {vac }}$ mutant phenotype is indeed caused by mutation of the Chpl gene, we performed an in vivo complementation assay. Transgenic mice were generated by pronuclear injection of a $200 \mathrm{~kb}$ wild-type BAC (RP23-222L23) containing the Chpl gene. In addition, this BAC also covers three other genes, but no polymorphisms were detected in their coding sequences nor were their expression levels altered in the $C h p 1^{\mathrm{vac} / \mathrm{vac}}$ cerebellum (Fig. $4 F$ and data not shown). Transgenic mice were bred with mice carrying the $C h p 1^{\text {vac }}$ mutation and their offspring were intercrossed to generate homozygous mutant mice with the BAC transgene ( $\left.\operatorname{Tg} 21 ; C h p 1^{\mathrm{vac} / \mathrm{vac}}\right)$. Immunohistochemistry with calbindin D-28 on cerebellar sections from 2- and 7-monthold Tg21;Chp $1^{\mathrm{vac} / \mathrm{vac}}$ mice failed to reveal axonal defects or soma loss in these mice (Fig. 4G-J). Moreover, Tg21;Chp1 $1^{\mathrm{vac} / \mathrm{vac}}$ mice displayed normal locomotor behavior that was indistinguishable from wild-type mice even after 1 year of age, suggesting that transgenic expression of Chpl was sufficient to rescue cerebellar defects in

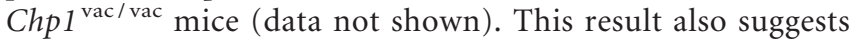
that the mutant $\mathrm{CHP} 1$ protein isoforms were not detrimental

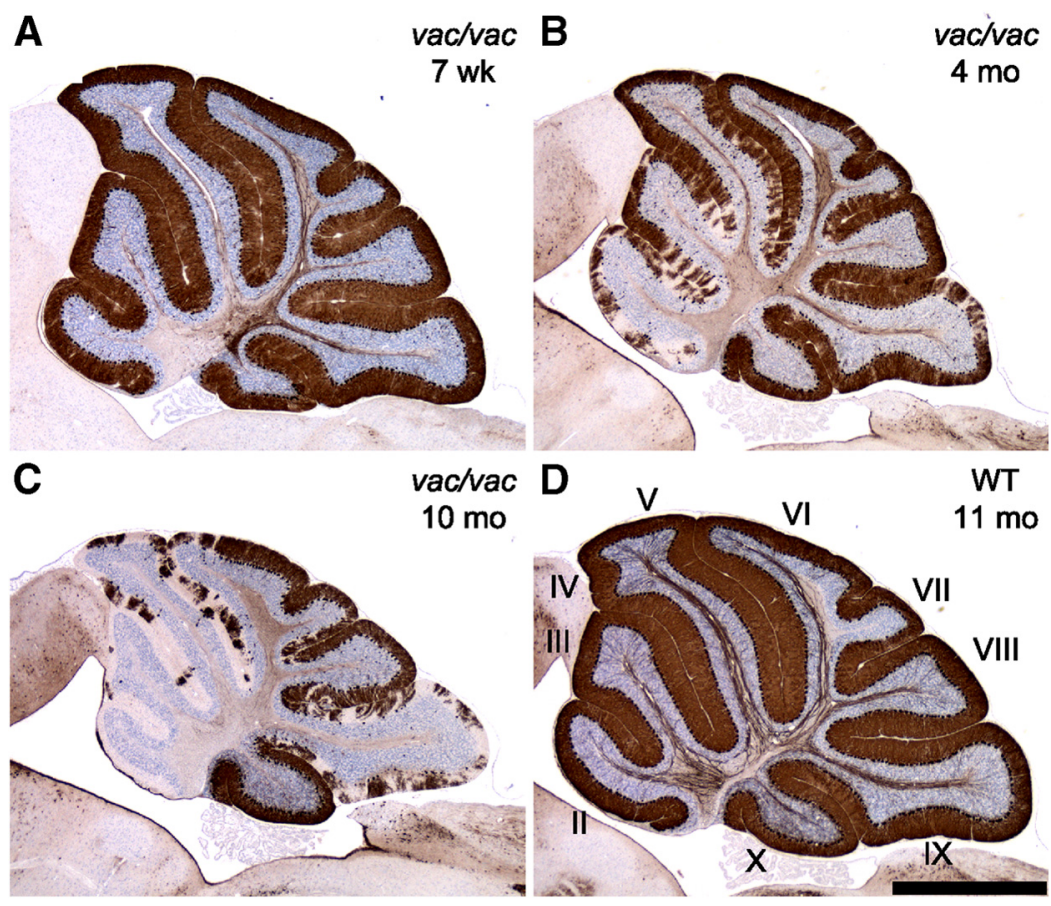

Figure 2. Progressive loss of Purkinje cells in the cerebellum of aged vac/vac mice. Sagittal sections of cerebella from 7-weekold $(\boldsymbol{A})$, 4-month-old $(\boldsymbol{B})$, and 10-month-old $(\boldsymbol{C})$ vac/vac and 11-month-old wild-type mice (WT; $\boldsymbol{D})$ were immunostained with antibodies to calbindin D-28. Cerebellar lobules are indicated by Roman numerals (D). Scale bar, $800 \mu \mathrm{m}$.
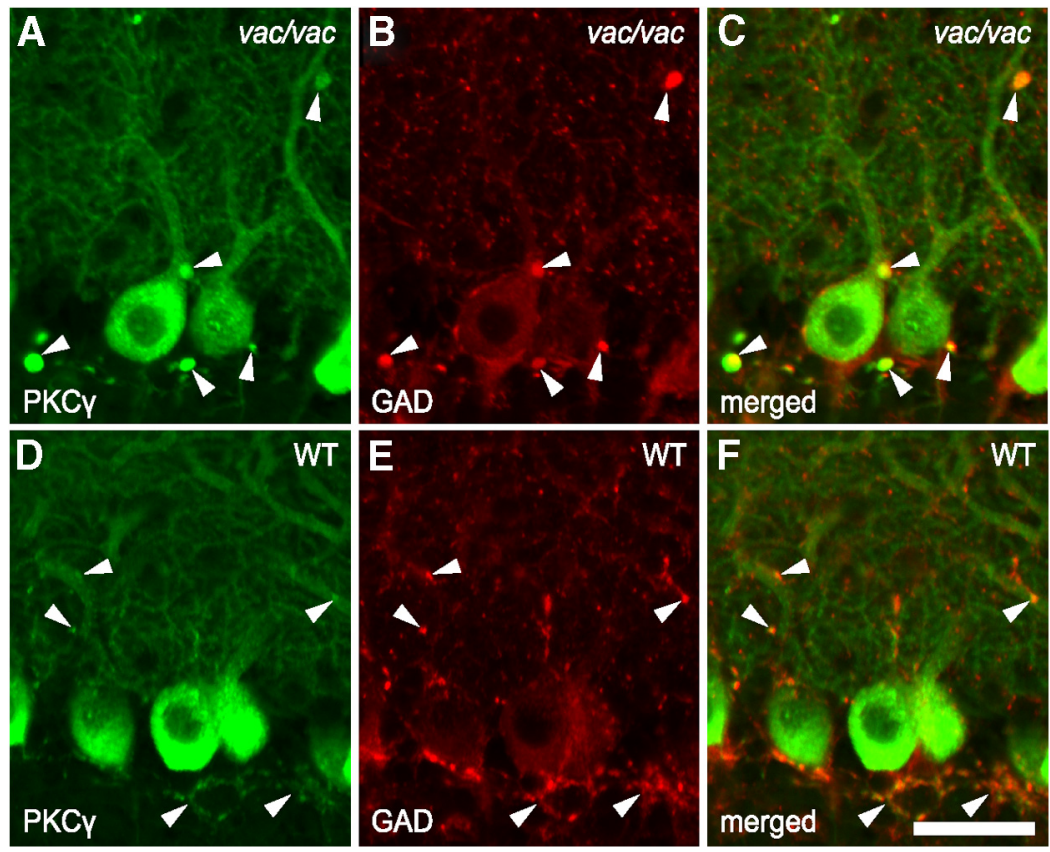

Figure 3. Early-onset degeneration of Purkinje cell axon collaterals in the vac/vac cerebellum. $\boldsymbol{A}-\boldsymbol{F}$, Representative images of coimmunofluorescence of P17 vac/vac $(\boldsymbol{A}-\boldsymbol{C})$ and wild-type (WT; $\boldsymbol{D}-\boldsymbol{F})$ cerebella with antibodies to PKC $\boldsymbol{\gamma}(\boldsymbol{A}, \boldsymbol{D})$ and GAD $(\boldsymbol{B}, \boldsymbol{E})$, and merged images $(\boldsymbol{C}, \boldsymbol{F})$. Purkinje cell axon collaterals are indicated by arrowheads. Note the swollen boutons of mutant axon collaterals ( $\boldsymbol{A}-\boldsymbol{C}$, arrowheads). Scale bar, $30 \mu \mathrm{m}$.

to neurons, consistent with the recessive inheritance of this mutation.

Mutation in Nhe1 leads to Purkinje cell axonal degeneration CHP1 has been shown to interact with and regulate members of the plasma membrane-localized NHEs in vitro and in cell-based assays (Di Sole et al., 2012). Interestingly, ataxia and selective 
A

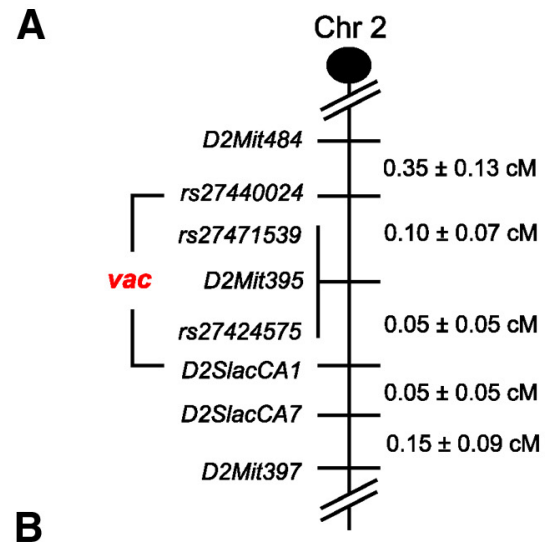

B

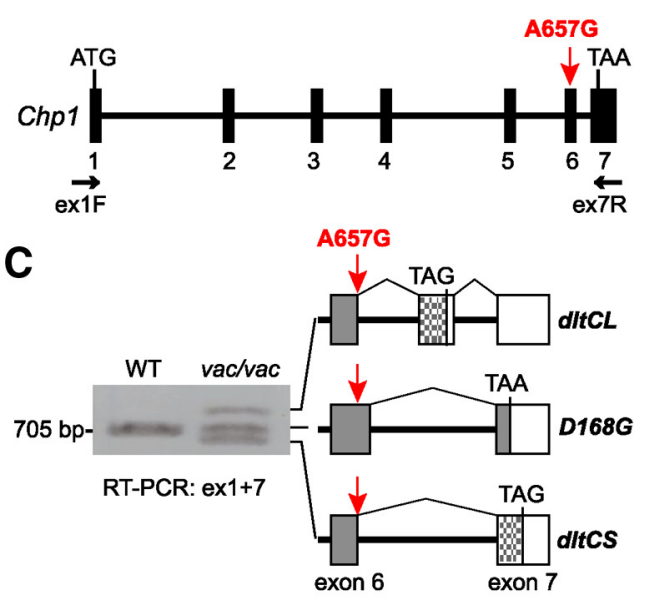

D

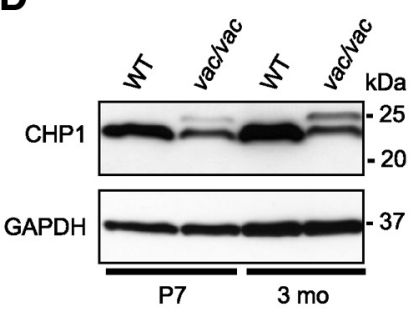

E

$\mathbf{F}$

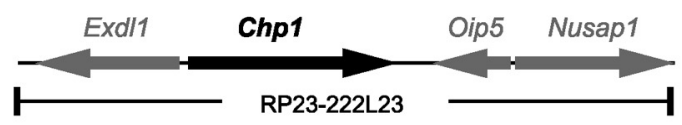

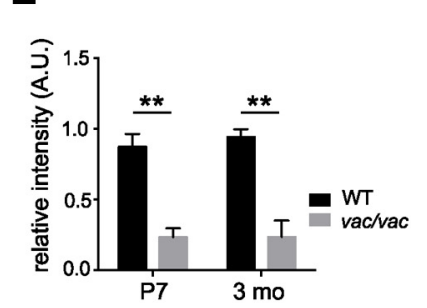

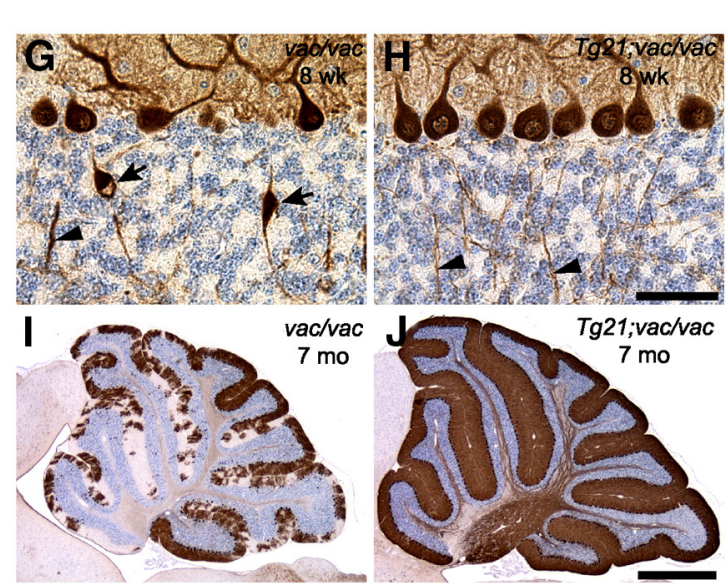

Figure 4. Identification of the vac mutation in the Chp1 gene. $\boldsymbol{A}$, The vac mutation was mapped to Chromosome 2 between rs27440024 and D2SlacCA1 (shown in cM \pm SEM). $B$, Schematic diagram of the mouse Chp 1 gene containing 7 exons with intervening sequences (not drawn to scale). The point mutation (A657G) was identified in exon 6. Primers used to amplify full-length cDNAs, ex1F and ex7R, are indicated. C, RT-PCR amplification of Chp1 transcripts in mutant and wild-type (WT) cerebellum. The diagram depicts the structure of each transcript. Shaded boxes represent coding sequence also found in the WT transcript; checked boxes are out-of-frame sequences unique to mutant transcripts; open boxes indicate $3^{\prime} U T R$ regions. $\boldsymbol{D}-\boldsymbol{E}$, Western blot analysis showing CHP1 protein in vac/vac and WT cerebella from P7 and 3-month-old mice. D, Representative blot from three experiments. GAPDH was used as a loading control. $\boldsymbol{E}$, The band intensity of total CHP1 proteins of each sample were quantified and normalized to that of GADPH. Values are the means of three experiment \pm SEM (error bars). Statistically significant $(p<0.01)$ differences between the WT and vac/vac cerebellum are indicated by asterisks. $\boldsymbol{F}$, Schematic illustration of genes encoded in the BAC (RP23-222L23) used to generate transgenic mice (drawn to scale). Arrows indicate transcriptional orientation of genes. $\mathbf{G}-\boldsymbol{J}$, Sagittal sections of cerebella immunostained with calbindin D-28 antibodies (brown) and counterstained with hematoxylin from vac/vac (G, $\boldsymbol{I}$ ) and transgenic $(\operatorname{Tg} 21) ; \operatorname{vac} / v a c(\boldsymbol{H}, \boldsymbol{J})$ mice at 8 weeks $(\boldsymbol{G}, \boldsymbol{H})$ and 7 months $(\boldsymbol{I}, \boldsymbol{J})$ of age. Scale bars: $\mathbf{G}, \boldsymbol{H}, 50 \mu \mathrm{m} ; \boldsymbol{I}, \boldsymbol{J}, 800 \mu \mathrm{m}$.

death of neurons were reported in both a spontaneously occurring mouse mutant allele (Nhe1 $\left.{ }^{\text {swe }}\right)$ and in a targeted allele of Nhe1, which is the most widely expressed NHE family member (Cox et al., 1997; Bell et al., 1999). These findings prompted us to hypothesize that disruption of this exchanger could underlie the phenotypes observed in the $C h p 1^{\text {vac/vac }}$ mouse.

To determine whether axon degeneration of Purkinje cells also occurs in Nhe1-deficient mice, we performed calbindin D-28 immunohistochemistry on cerebellar sections from P21 Nhe $1^{\text {swe/swe }}$ and wild-type mice. Similar to $C h p 1^{\mathrm{vac} / \mathrm{vac}}$ mice, Purkinje cell axons in the Nhe1 mutant cerebella were hypertrophic with increased expression of NFM compared with wild-type axons (Fig. 5A-F). Because degeneration of Purkinje cell axon collaterals was among the earliest pathological features in the $C h p 1^{\mathrm{vac} / \mathrm{vac}}$ cerebellum, we assessed local PKC $\gamma$ expression in Purkinje cell axons by immunofluorescence on cerebellar sections from P8 to P21 Nhe $1^{\text {swe/swe }}$ mice. Indeed, swollen and displaced collateral boutons were identified as early as P14 in the Nhe $1^{\text {swe/swe }}$ cerebellum and these abnormalities became more pronounced with age (Fig. 5G-I and data not shown).

To determine whether ablation of Nhe1, like mutation of Chp1, causes loss of Purkinje cells in aged mice, cerebella from 4-month-old $N$ he $1^{\text {swe/swe }}$ mice were analyzed by calbindin-D28 immunohistochemistry. By this age, most Purkinje cell axons had degenerated in these mice, as shown by the near complete absence of calbindin-positive Purkinje cell axon tracts within the white matter and the presence of many hypertrophic axon fragments in the granule cell layer (Fig. 5J-L). Surprisingly, in contrast to $C h p 1^{\text {vac }}$ mutant mice, no loss of Purkinje cells was observed in the Nhe $1^{\text {swe/swe }}$ cerebellum. These results indicate that axon degeneration and cell death of Purkinje cells are likely two discrete processes and that NHE1 function is critical for the former, but not the latter, event.

\section{CHP1 is required for biosynthetic maturation of NHE1}

NHE1 is a principle plasma membrane target for CHP1 (Lin and Barber, 1996; Pang et al., 2001). The striking similarity of Purkinje cell axonal defects in $C h p 1^{\mathrm{vac} / \mathrm{vac}}$ and $N h e^{\text {swe / swe }}$ mice suggests that the axonal abnormalities observed in the Chp1 mutant cerebellum are mediated by disruption of NHE1 activity. CHP1 binds the juxtamembrane region of NHE1 via a hydrophobic pocket opposite the EF hands (Mishima et al., 2007). Upon NHE1 binding, the $\mathrm{Ca}^{2+}$ affinity of the two functional EF-hand domains (EF3 and EF4) in CHP1 increases. Disruption of either 

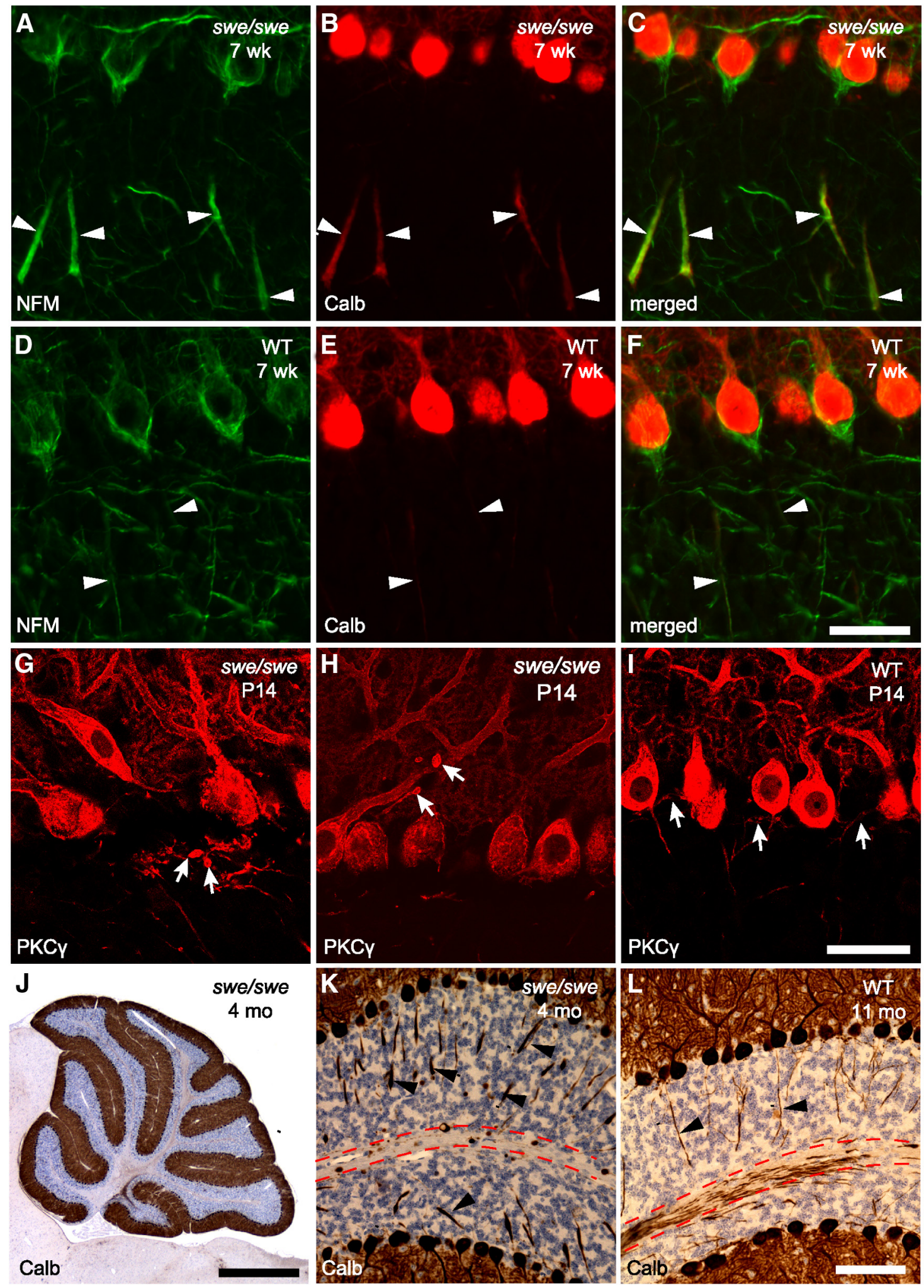

Figure 5. NHE1 deficiency causes degeneration of Purkinje cell axons without loss of cell bodies. $\boldsymbol{A}-\boldsymbol{C}$, Hypertrophic axons (arrowheads) in the 7-week-old Nhe1 ${ }^{\text {swe/ swe }}$ (swe/swe) cerebelllum. These axons display intraaxonal accumulation of the neurofilament subunit NFM $(\boldsymbol{A})$ and are reactive with calbindin D-28 antibodies ( $\boldsymbol{B}$; merge in $\boldsymbol{C}$ ). Representative Purkinje cell axons in the wild-type (WT) cerebellum are indicated by arrowheads in D-F. G-I, Degeneration of Purkinje cell axon collaterals in Nhe $1^{\text {swe/ swe }}$ cerebellum occurred from P14 as shown by PKC $\gamma$ immunostaining. Note the swollen collateral boutons ( $\boldsymbol{G}$, arrows) and misplaced collateral projections ( $\boldsymbol{H}$, arrows) observed in Nhe $1^{\text {swe/swe }}$ but not the WT cerebellum (I). Arrows in $\boldsymbol{I}$ indicate representative WT collateral boutons. $\boldsymbol{J}-\boldsymbol{L}$, Sagittal sections of 4-month-old Nhe ${ }^{\text {swe/swe }}(\boldsymbol{J}, \boldsymbol{K})$ and wild-type $(\boldsymbol{L})$ cerebella were immunostained with calbindin-D28 antibodies (brown). $\boldsymbol{J}$, Lower-magnification image showing the absence of Purkinje cell death in the Nhe $1^{\text {swe/swe }}$ cerebellum. $\boldsymbol{K}$, Higher-magnification image showing extensive Purkinje cell axon degeneration, indicated by the absence of calbindin

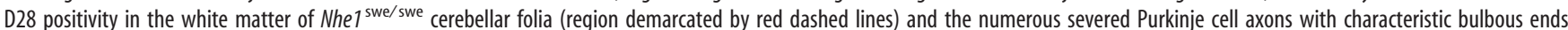
(arrowheads) in the granule layer. $L$, Purkinje cell axons in the WT cerebellum are slender and plenty (arrowheads and region demarcated by red dashed lines). Sections were counterstained by hematoxylin. Scale bars: $\boldsymbol{A}-\boldsymbol{F}, 40 \mu \mathrm{m} ; \boldsymbol{G}-\boldsymbol{I}, 30 \mu \mathrm{m} ; \boldsymbol{J}, 800 \mu \mathrm{m} ; \boldsymbol{K}, \boldsymbol{L}, 80 \mu \mathrm{m}$. 
A

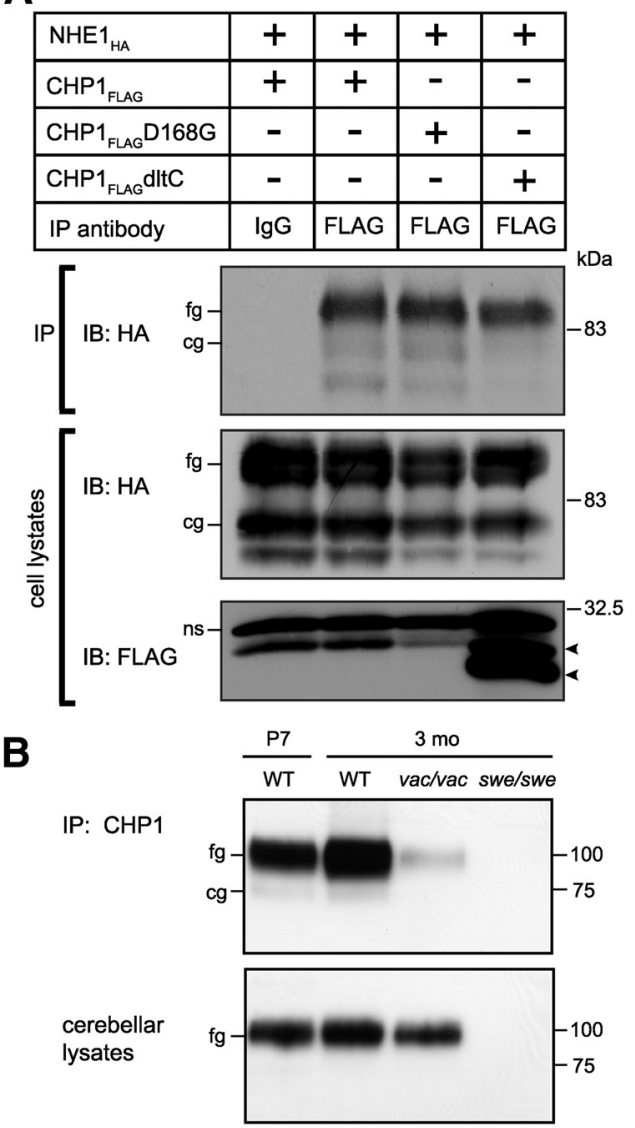

IB: NHE1

Figure 6. CHP1-D168G and dltC mutants form a complex with NHE1 in transfected cells and the mouse cerebellum. $A, A P-1$ cells stably expressing $\mathrm{NHE}_{\mathrm{HA}}$ were transiently transfected with either wild-type or mutant (D168G and dltC) constructs of CHP1 3FLAG. $_{\text {. }}$. ll lysates were immunoprecipitated (IP) with rabbit anti-FLAG antibodies or nonspecific rabbit antibody (IgG) as a negative control. Cell lysates and IPs were immunoblotted (IB) using mouse anti-HA or FLAG antibodies. The two bands visualized in the $\mathrm{NHE}_{\mathrm{HA}}$ blots represent the immature coreglycosylated $(\mathrm{cg})$ and mature fully glycosylated $(\mathrm{fg})$ forms of the exchanger. In the $\mathrm{CHP1}_{3 \mathrm{FLAG}}$ blots, a single band was detected for the wild-type and D168G constructs ( $\sim 22 \mathrm{kDa})$, whereas two bands were detected for the dltC construct ( $\sim 22$ and $\sim 20 \mathrm{kDa}$ ), all indicated by arrowheads. In addition, a nonspecific band (ns) was detected at $\sim 30 \mathrm{kDa}$ in all lysates. Data shown are representative of three separate experiments. $\boldsymbol{B}$, Cerebellar lysates from P7 wild-type and adult wild-type, Chp $1^{\mathrm{vac} / \mathrm{vac}}$ ( vac/vac), and $\mathrm{Nhe}^{\text {swe/swe }}$ (swe/swe) mice were immunoprecipitated with rabbit polyclonal antibodies to CHP1. The lysates and IPs were detected by immunoblotting with mouse monoclonal antibody to NHE1.

$\mathrm{Ca}^{2+}$-binding domain, while not impairing its ability to bind NHE1, significantly reduces the intracellular $\mathrm{pH}$ sensitivity and activity of NHE1 and blunts its activation by various stimuli (Pang et al., 2004).

To confirm that mutant forms of CHP1 retain their ability to interact with NHE1, Chinese hamster ovary AP-1 cells that stably express $\mathrm{NHE}_{\mathrm{HA}}$ were transiently transfected with triple FLAG epitope-tagged constructs encoding wild-type, D168G, and dltC forms of CHP1. Both the mature, fully glycosylated form of NHE1 and, to a lesser extent, the immature, core-glycosylated form of NHE1 were immunoprecipitated by wild-type and mutant $\mathrm{CHP}_{3 \mathrm{FLAG}}$ constructs, demonstrating that mutant $\mathrm{CHP} 1$ isoforms still interact with NHE1 (Fig. 6A). However, the total cellular levels of $\mathrm{NHE}_{\mathrm{HA}}$ were noticeably reduced $(\sim 30-50 \%$ as measured by densitometry) in cells that overexpressed the mutant constructs compared with those expressing wild-type $\mathrm{CHP}_{3 \mathrm{FLAG}}$ constructs.
To determine whether CHP1 and NHE1 interact in vivo, we performed coimmunoprecipitation assays using cerebellar extracts from P7 and 3-month-old wild-type mice. Indeed, NHE1, the majority of which is fully glycosylated in the cerebellum, was immunoprecipitated with CHP1 antibodies, confirming that CHP1 is complexed with NHE1 in the developing and adult cerebellum (Fig. 6B). In addition, NHE1 was also immunoprecipitated from $C h p 1^{\mathrm{vac} / \mathrm{vac}}$ cerebellum by CHP1 antibodies, although at reduced levels. This reduction in immunoprecipitated NHE1 may be indicative of a reduced affinity of mutant CHP1 for NHE1 in vivo or it may simply reflect the reduced levels of mutant CHP1 isoforms in the Chp $1^{\mathrm{vac} / \mathrm{vac}}$ cerebellum.

Recent studies have indicated that CHP1 and other CHP family members promote the oligosaccharide maturation and trafficking of NHE1 from the endoplasmic reticulum to the plasma membrane as well as its stability (Zaun et al., 2008; Matsushita et al., 2011). Because the bulk of fully glycosylated NHE1 resides at the plasma membrane whereas the core-glycosylated species remains intracellular (Aharonovitz et al., 2000; Zaun et al., 2008), the glycosylation status of the exchanger can be used as a convenient indicator of its posttranslation processing and trafficking to the cell surface.

To determine whether the CHP1 mutant isoforms affect the biosynthetic processing of NHE1, AP-1 cells were transiently cotransfected with constructs encoding HA-tagged Nhe1 and FLAG-tagged wild-type or mutant forms of Chp1. Cell lysates were collected at various time points after transfection and Western blot analysis was performed to detect the expression of NHE1. As shown in Figure 7, $A$ and $B$, coexpression of wild-type CHP1 led to a significant increase in the ratio of fully glycosylated to core-glycosylated NHE1 compared with control cells that were only cotransfected with empty vector $(p<0.05)$. A similar increase was observed when cells were cotransfected with a construct encoding the $\mathrm{CHP} 1^{\mathrm{D} 168 \mathrm{G}}$ isoform. However, expression of the EF4-truncated $\mathrm{CHP} 1^{\text {dltC }}$ isoform failed to alter the ratio of mature versus immature NHE1 forms, suggesting that this form of CHP1 is defective in promoting the synthesis of the fully glycosylated exchanger. Similar results were obtained in transfected HEK293T cells (data not shown).

To determine whether NHE1 maturation is disrupted by the CHP1 mutation in vivo, we examined NHE1 levels in the wildtype and $C h p 1^{\mathrm{vac} / \mathrm{vac}}$ cerebellum. Given the early onset of Purkinje axon defects in both the $N h e 1^{\text {swe/swe }}$ and $C h p 1^{\mathrm{vac} / \mathrm{vac}}$ mutants, cerebellar extracts were generated from mice at 1,2 , and 3 weeks of age. In the 1 -week-old $C h p 1^{\mathrm{vac} / \mathrm{vac}}$ mouse cerebellum, the NHE1 level was reduced to $20 \%$ of the wild-type, consistent with our in vitro finding that mutant $\mathrm{CHP} 1$ is less efficient in promoting the maturation of NHE1 (Fig. 7C,D).

Surprisingly, levels of NHE1 greatly increased during postnatal development of the $C h p 1^{\text {vac/vac }}$ cerebellum. In the cerebella of 2 - and 3 -week-old mutant mice, NHE1 was $75 \%$ and $71 \%$ of wild-type levels, respectively, indicating that a protein other than CHP1 promotes NHE1 maturation during later cerebellar development. CHP3 has been detected in the adult brain, whereas CHP2 was only detected in the intestine and a few cancer cell lines (Pang et al., 2002; Gutierrez-Ford et al., 2003; Inoue et al., 2003). Therefore, we examined CHP3 levels at various time points in the postnatal cerebellum. Western blot analysis demonstrated that, unlike CHP1, the levels of CHP3 was low at 1 week, but dramatically increased at 2 and 3 weeks, suggesting that CHP3 compensates for the loss of $\mathrm{CHP} 1$ during late postnatal cerebellar development. 
Membrane expression of CHP1 is dependent on NHE1

To determine how disruption of NHE1/ CHP1 affects Purkinje cell axon survival, we investigated the localization of CHP1 and NHE1 in the cerebellum by immunofluorescence. In the wild-type cerebellum at P8, just before the occurrence of the axonal defects in the $\operatorname{Ch} p 1^{\text {vac/vac }}$ cerebellum, strong CHP1-positive puncta were observed in the deep white matter surrounding the deep cerebellar nuclei (DCN). These puncta were reminiscent of Purkinje cell axon terminals that form GABAergic synapses with the DCN (Fig. $8 A$ ). The expression of $\mathrm{CHP} 1$ at Purkinje cell presynaptic terminals was confirmed by the overlapping immunostaining pattern of CHP1 and calbindin D-28 (Fig. 8B,C). The specificity of the CHP1 antibodies for immunohistochemistry was confirmed by immunostaining of $C h p 1^{\text {vac/vac }}$ cerebella, in which no signal was detected, which was consistent with earlier Western blot results (data not shown).

To determine whether NHE1 is required for presynaptic localization of $\mathrm{CHP} 1$, we performed immunostaining of CHP1 in the Nhe1 ${ }^{\text {swe/swe }}$ cerebellum. In the absence of NHE1, CHP1 expression was significantly reduced in Purkinje cell axon terminals within the deep white matter (Fig. $8 D-F$ ). Similar results were obtained by coimmunofluorescence of CHP1 and GAD in the cerebellar DCN region (data not shown). In addition to expression in the Purkinje cell axon terminals, CHP1 was expressed prominently in the cytoplasm of both Purkinje cells and DCN neurons (Fig. $8 A, G$ ). Interestingly, the cytoplasmic expression of CHP1 in mutant Purkinje cells and DCN neurons was not obviously altered, suggesting that depletion of NHE1 specifically affects the presynaptic, but not the intracellular, localization of CHP1 (Fig. 8D,J).

CHP1 localization to axon terminals was not limited to Purkinje cells, but was also observed in a wide variety of other neurons in the brain throughout development, as exemplified by the localization of CHP1 in the pinceau synapses of basket cell axons and mossy fibers and their terminals in the inner granule cell layer of the adult wild-type cerebellum (Fig. $8 M-O$ and data not shown). Similarly, depletion of NHE1 greatly decreased the axonal localization of CHP1 in these regions (Fig. $8 P-R$ ), suggesting that NHE1 serves as a membrane anchor for enrichment of CHP1 at several presynaptic terminals of axons in the brain.

The requirement of NHE1 for plasma membrane localization of CHP1 was fur-
A
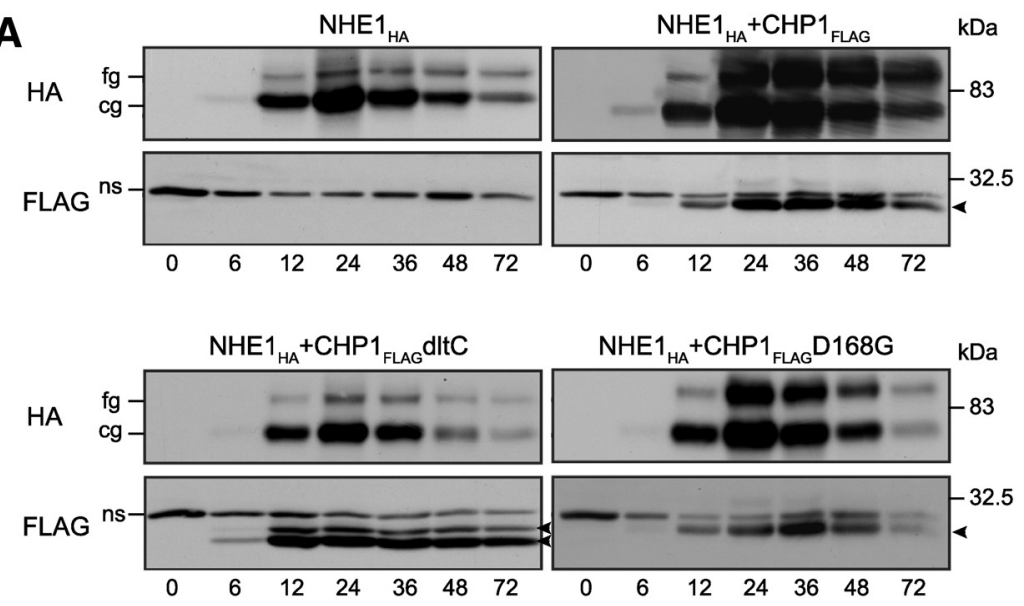

B
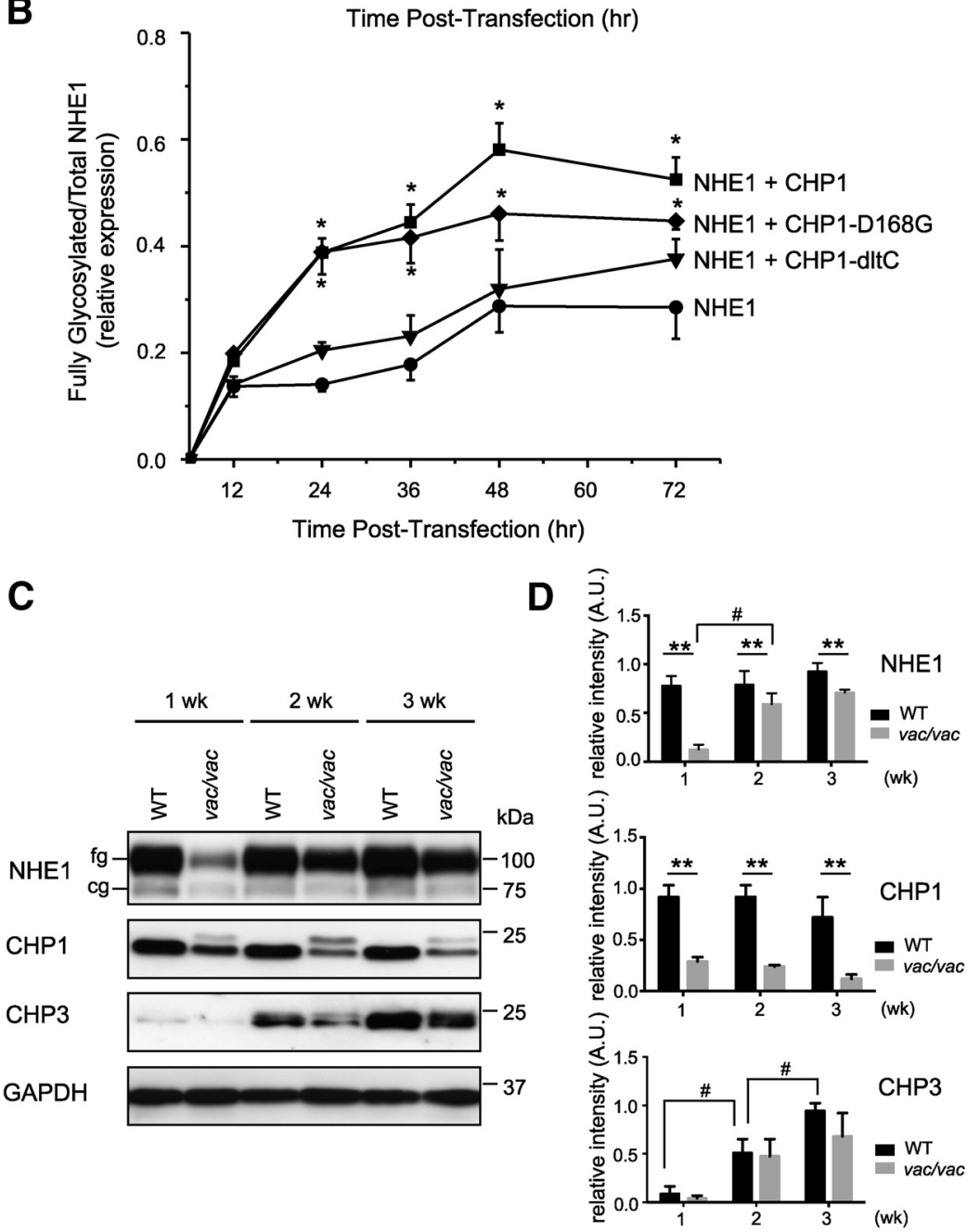

Figure 7. Effect of mutant CHP1 proteins on the biosynthetic maturation of NHE1. A, B, AP-1 cells were transiently cotransfected with equal quantities of NHE1 ${ }_{\mathrm{HA}}$ and empty vector (pCDNA3) or variants of $\mathrm{CHP1}_{3 \mathrm{FLAG}}$ (wild-type, D168G, and dltC). $A$, Cell lysates were prepared at the indicated time points after transfection and immunoblotted to detect expression of $\mathrm{NHE}_{\mathrm{HA}}$ and $\mathrm{CHP1}_{3 \mathrm{FLAG}}$. Data shown are representative of three independent experiments. $\boldsymbol{B}$, Densitometric analysis of the data presented in $\boldsymbol{A}$ comparing the relative expression levels of NHE1 (presented as ratios of fully glycosylated to total $\mathrm{NHE}_{\mathrm{HA}}$ as a function of time posttransfection). Values represent the mean \pm SEM of three experiments. Statistically significant differences $(p<0.05)$ between variants of $\mathrm{CHP}_{3 \mathrm{FLAG}}$ and empty vector are indicated with an asterisk. $C, D$, Western blot analysis showing levels of NHE1,

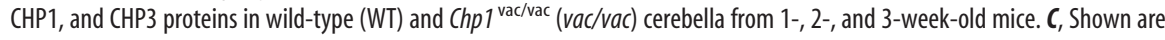
representative blots from three separate experiments. GAPDH is included as a loading control. $\boldsymbol{D}$, Densitometric analysis of the data presented in C comparing the relative expression level of NHE1, CHP1, and CHP3 in WT and vac/vac cerebella at different postnatal ages. Results are presented as mean \pm SEM $(n=3)$. ${ }^{*}$ Statistically significant $(p<0.01)$ differences between WT and mutant cerebellum; " statistically significant $(p<0.01)$ differences between time points. 

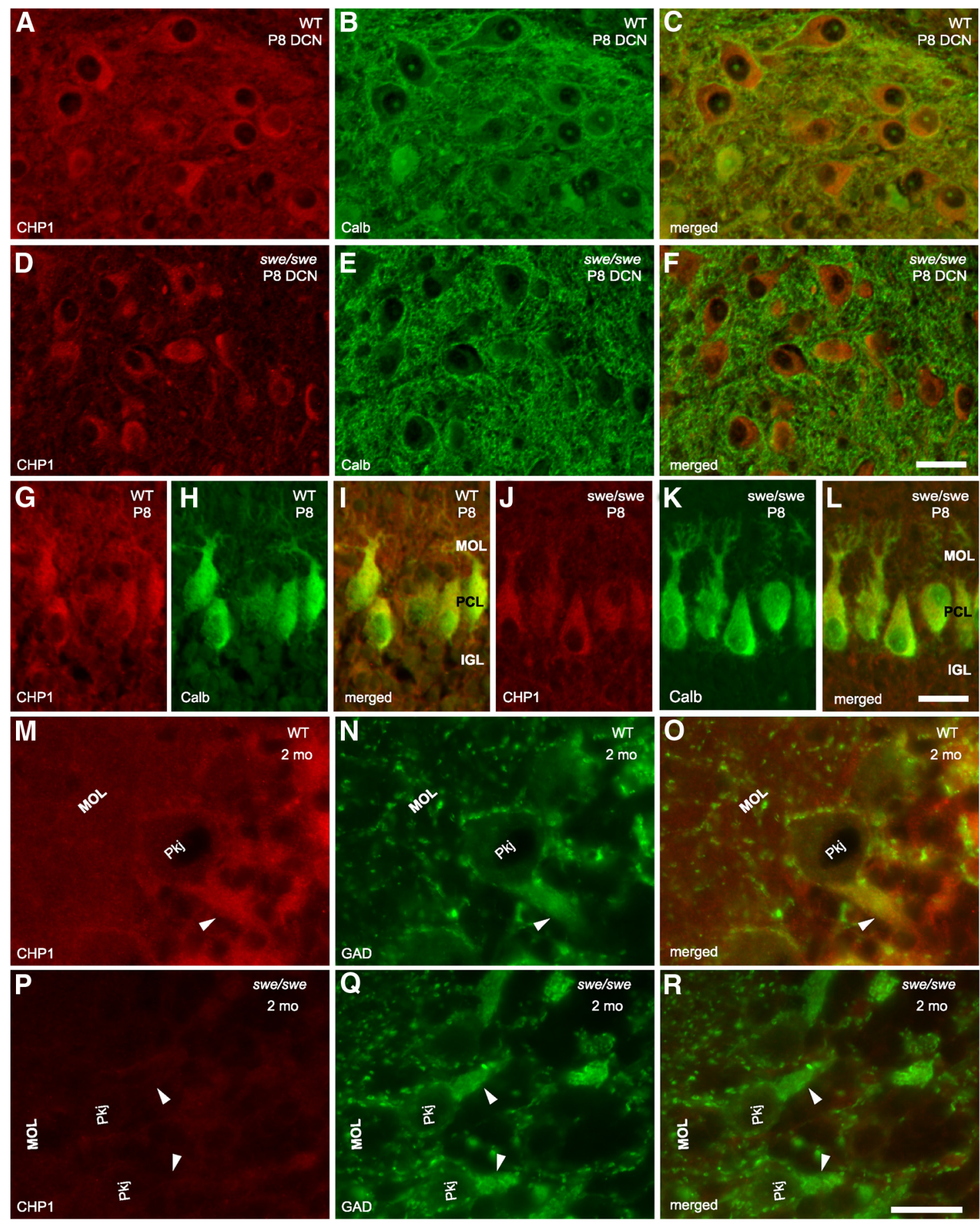

Figure 8. The localization of CHP1 at axon terminals is dependent on NHE1. Representative images of sagittal sections of P8 wild-type (WT; $\boldsymbol{A}-\boldsymbol{C}, \mathbf{G}-\boldsymbol{I})$ and Nhe ${ }^{\text {swe/swe }}$ (swe/swe; $\mathbf{D}-\boldsymbol{F}, \boldsymbol{J}-\boldsymbol{L}$ ) cerebella were immunostained with antibodies to $C H P 1(A, D, G, J)$ and calbindin D-28 (to label Purkinje cells and their axon terminals that synapse onto the DCN neurons in the deep cerebellar white matter, as visualized by the punctate staining surrounding the DCN neurons; $\boldsymbol{B}, \boldsymbol{E}, \boldsymbol{H}, \boldsymbol{K})$. Merged images are shown in $\boldsymbol{C}, \boldsymbol{F}, \boldsymbol{I}, \boldsymbol{L}$. $\boldsymbol{A}-\boldsymbol{C}$, Note the strong CHP1 immunoreactivity in the cell body and processes of the DCN neurons, as well as the punctate CHP1 staining surrounding the DCNs that overlaps with calbindin signals in the WT cerebellum. $\boldsymbol{D}-\boldsymbol{F}$, In the Nhe $1^{\text {swe/swe }}$ cerebellum, CHP1-positive signals were greatly decreased in areas surrounding the DCN neurons, but still present in the DCN soma and processes. $G-L$, Purkinje cells in the cerebellar cortex are positive for CHP1 both in the WT $(\boldsymbol{G}-\boldsymbol{I})$ and swe/swe mouse $(\boldsymbol{J}-\boldsymbol{L}) \cdot \boldsymbol{M}-\boldsymbol{R}$, Double immunofluorescence staining with antibodies to CHP1 $(\boldsymbol{J}, \boldsymbol{M})$ and $\mathrm{GAD}(\boldsymbol{K}, \boldsymbol{N})$ and merged images $(\boldsymbol{L}, \mathbf{0})$ in 2 -month-old WT $(\boldsymbol{J}-\boldsymbol{L})$ and Nhe $1^{\text {swe/swe }}(\boldsymbol{M}-\mathbf{0})$ cerebellar sections. Arrows point to the pinceau synapses that were recognized by their GAD positivity, their distinctive pinceau (paintbrush) shape, and their location around the Purkinje (Pkj) axon hillock. Mol, molecular layer; PCL, Purkinje cell layer; IGL, inner granule cell layer. Camera exposure times were equal for images of the same channel. Scale bars: $\boldsymbol{A}-\boldsymbol{F}, 25 \mu \mathrm{m}$; $\mathbf{G}-\boldsymbol{R}, 20 \mu \mathrm{m}$.

ther examined by subcellular fractionation and Western blot analysis. P8 wild-type, Nhe $1^{\text {swe/swe }}$, and $C h p 1^{\text {vac/vac }}$ cerebellar lysates were separated into cytoplasmic and crude synaptosomal membrane fractions by differential centrifugation. The efficiency of the separa- tion was demonstrated by the relative enrichment of the PCMA (plasma membrane), syntaxin-1 (presynaptic membrane), and Hsp90 (cytosolic) proteins (Fig. 9). These results demonstrated that NHE1 was abundant in the membrane, but not the cytoplasmic 
fraction, and that levels of NHE1 were greatly reduced in the $C h p 1^{\text {vac/vac }}$ cerebellum. Conversely, CHP1 was present in both the membrane and cytosolic fractions, with $\sim 88 \%$ and $\sim 12 \%$ of total CHP1 in these fractions, respectively. In the Nhe $1^{\text {swe/swe }}$ cerebellum, CHP1 was decreased in both its overall level and in the membrane fraction compared with the wild-type cerebellum. However, no change was observed in the cytosolic levels of CHP1 between the Nhe $1^{\text {swe/swe }}$ and wild-type cerebellum, suggesting that the membrane, but not the cytoplasmic, localization of CHP1 is largely dependent on NHE1 in vivo.

\section{CHP1 is required for NHE1 localization} at a subset of presynaptic terminals

To further illustrate the nature of CHP1 and NHE1 interactions, we investigated the effect of the $C h p 1^{\text {vac }}$ mutation on the subcellular distribution of NHE1 in the mouse cerebellum. Similar to CHP1, strong NHE1 immunoreactivity was detected in Purkinje cell axon terminals in the P8 wild-type cerebellum, as indicated by the punctate staining of NHE1 that overlapped with that of calbindin D-28 in the deep white matter (Fig. 10A-C). Coimmunofluorescence using antibodies to NHE1 and CHP1 also demonstrated significant overlap of signals (data not shown). The expression of NHE1 was greatly reduced in the deep white matter of the P8 Chp1 $1^{\mathrm{vac} / \mathrm{vac}}$ cerebellum, indicating that the Chp $1^{\text {vac }}$ mutation disrupts the presynaptic localization of NHE1 in Purkinje cell axons (Fig. 10D-F). The specificity of the NHE1 antibody was confirmed by the absence of NHE1-positive signal in Nhe $1^{\text {swe/swe }}$ brain sections (Fig. 10G-I).

The effect of the Chp1 ${ }^{\text {vac }}$ mutation on the membrane distribution of NHE1 was further explored by comparison of the NHE1 immunostaining pattern in adult wild-type and $C h p 1^{\text {vac/vac }}$ cerebella. In the cerebella of 2-month-old wild-type mice, NHE1 expression was detected in multiple axonal structures, including the pinceau synapses, mossy fibers and their terminals, and parallel fibers (Fig. 10J-L). In the Chp $1^{\text {vac/vac }}$ cerebellum, NHE1 was not detectable in pinceau synapses, but was still present in mossy fibers and parallel fibers (Fig. 10M-O). These data suggest that disruption of CHP1 specifically affects membrane expression of NHE1 in a subset of neurons, mostly likely through decreasing the synthesis of the fully glycosylated form of the protein.

\section{Discussion}

Axon degeneration is an early and potentially causal event in a variety of human neurodegenerative disorders. However, the molecular mechanisms that initiate the degenerative process of axons are largely unknown. Here, we identified a novel ataxic mouse mutant, vacillator, which displays extensive degeneration of cerebellar Purkinje cell axons. By positional cloning, we identified the vacillator mutation in the Chp1 gene, which encodes an EF-hand $\mathrm{Ca}^{2+}$-binding protein, a positive regulator of sodium hydrogen exchangers. We further showed that mutation of Chp1 affected the synthesis of fully glycosylated NHE1 and cell surface expression of this protein. Therefore, NHE1 localization at the axon terminals of Purkinje cells was severely decreased in the
Chp $1^{\text {vac/vac }}$ cerebellum. In fact, upon examination of Nhe1deficient mice, we discovered that Purkinje cell axons degenerate in these mice, confirming the importance of NHE1 for axon homeostasis.

The relationship of axon degeneration and neuronal loss has been debated due to the intricacy of many neurodegenerative disorders (Medana and Esiri, 2003; Coleman, 2005; Saxena and Caroni, 2007). Here we provide further evidence to support the idea that, at least in a subset of neurodegenerative disorders, disturbances of discrete cellular pathways may underlie axon degeneration and cell death. Axonal degeneration occurs in the postnatal cerebellum of Chp $1^{\mathrm{vac} / \mathrm{vac}}$ mice, with neuronal loss occurring much later. In contrast, Nhe $1^{\text {swe/swe }}$ mice have early Purkinje axonal loss without cell body degeneration. Therefore, it is apparent that axon degeneration of Purkinje cells can be separable from death of these neurons, a finding consistent with a previous observation that acute axotomy in the adult rat cerebellum did not induce Purkinje cell loss (Dusart and Sotelo, 1994). The mechanisms for the late-onset death of Chp1-deficient Purkinje cells remain unclear. In addition to NHE1, CHP1 complexes with other NHEs, regulating their plasma membrane localization (Pang et al., 2001; Di Sole et al., 2009; Y.L. and S.L.A., unpublished observations). In the Purkinje cells of the adult rat cerebellum, transcripts of NHE2-4 are also present and likely participate in regulating the intracellular $\mathrm{pH}$ of the Purkinje cell soma (Ma and Haddad, 1997; Lein et al., 2007). Therefore, deficiency of CHP1 may cause Purkinje cell loss by compromising the activities of all NHE isoforms in the adult Purkinje cell.

CHP1 consists of four EF hands; however, only EF3 and EF4 are capable of binding calcium ions (Lin and Barber, 1996). All three CHP1 mutant isoforms harbor an amino acid substitution at the $z$ position of EF4, one of the six EF-hand amino acid residues that are involved in the $\mathrm{Ca}^{2+}$ binding. The $C h p 1^{\text {vac }}$ mutation also causes abnormal splicing that leads to trunca- 

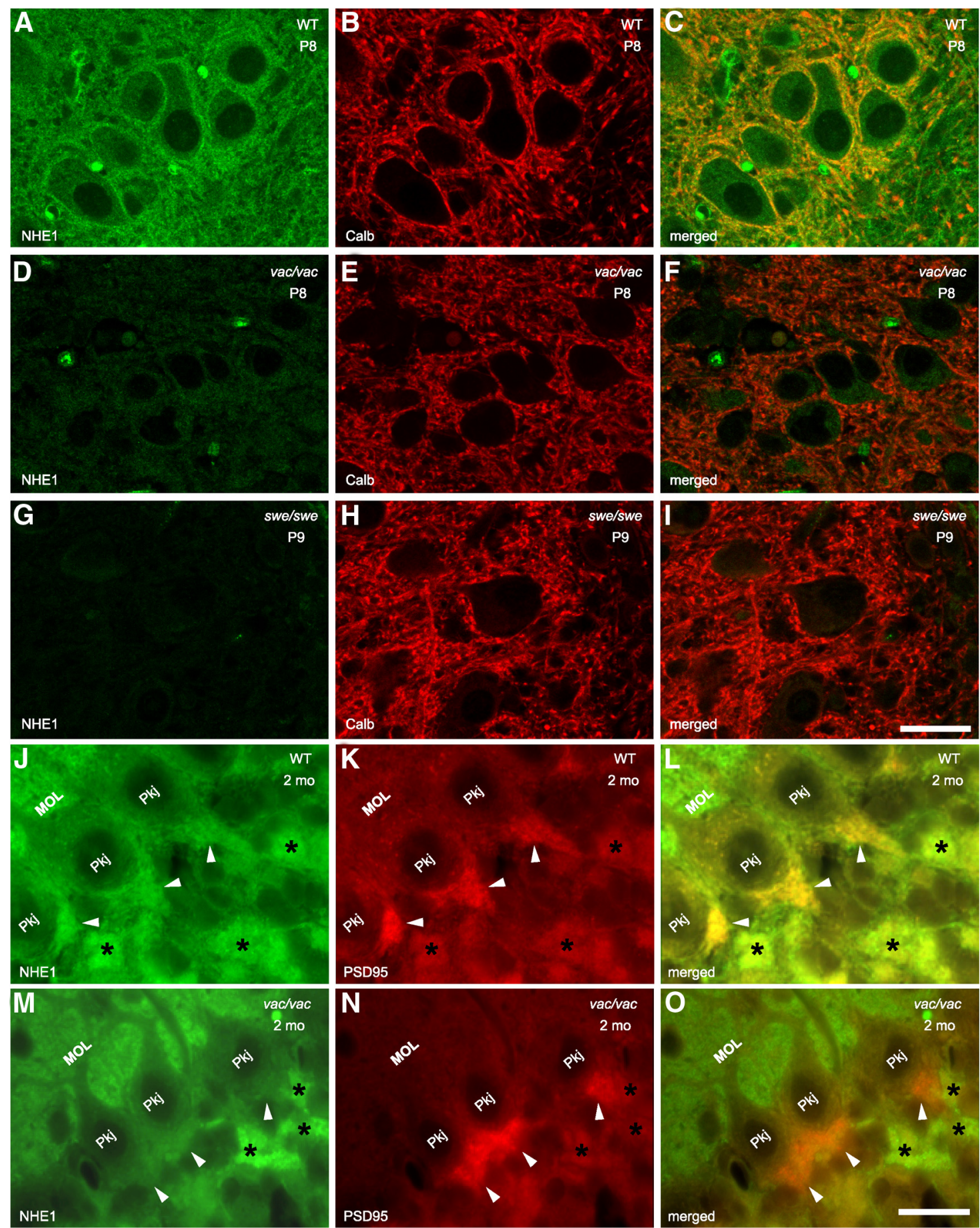

Figure 10. CHP1 is necessary for NHE1 localization in a subset of axon terminals. Representative images of the cerebellar DCN region of P8 wild-type (WT; $\boldsymbol{A}-\boldsymbol{C})$, Chp 1 vac/vac (vac/vac; $\mathbf{D}-\boldsymbol{F})$, and P9 Nhe $1^{\text {swe/swe }}$ (swe/swe; $\left.\mathbf{G}-\boldsymbol{I}\right)$ mice coimmunostained with anti-NHE1 $(\boldsymbol{A}, \boldsymbol{D}, \boldsymbol{G})$ and anti-calbindin D-28 (Calb) antibodies $(\boldsymbol{B}, \boldsymbol{E}, \boldsymbol{H})$. Merged images are shown in $\boldsymbol{C}, \boldsymbol{F}, \boldsymbol{I}$. In the deep white matter of the WT cerebellum, NHE1 immunoreactivity was observed surrounding DCN neurons ( $\boldsymbol{A}$ ), the area of Purkinje cell presynaptic formation shown by calbindin D-28 staining ( $\boldsymbol{B}$ and merge in $\boldsymbol{C}$ ). NHE1 immunoreactivity was dramatically reduced in the $C h p 1^{\text {vac/vac }}$ deep cerebellar white matter $(\boldsymbol{D})$ and was not observed in the $D C N$ region of Nhe $1^{\text {swe/swe }}$ cerebella $(\boldsymbol{G})$, the latter validating the specificity of the mouse anti-NHE1 antibody. $\boldsymbol{J}-\mathbf{0}$, Coimmunofluorescence with antibodies to NHE1 $(\boldsymbol{J}, \boldsymbol{M})$ and PSD95 $(\boldsymbol{K}, \boldsymbol{N})$ and merged images $(\boldsymbol{L}, \mathbf{0})$ in wild-type $(\boldsymbol{J}-\boldsymbol{L})$ and $C h p{ }^{\text {vac/vac }}(\boldsymbol{M}-\mathbf{0})$ cerebellar sections. Arrows point to pinceau synapses that were recognized by their PSD95 positivity, unique shape, and location. Asterisks indicate cerebellar glomeruli. Camera exposure times were equal for images of the same channel. Scale bar, $20 \mu \mathrm{m}$.

tion of the second half of EF4 in two mutant isoforms (dltCS and dltCL). Unlike the D168G isoform, the dltC isoforms completely lack the ability to promote the full glycosylation and membrane expression of NHE1. Furthermore, although the total level of mutant transcripts was unchanged, all three mutant proteins displayed reduced protein levels in the cere- bellum, suggesting that even though the D168G CHP1 isoform is competent to promote NHE1 maturation, it has reduced stability. These data suggest that the vac mutation is a severe hypomorphic, rather than a null, allele of Chp1. We suspect that complete loss of CHP1 may cause more severe or broader defects than this allele. 
Our observations that NHE1 levels were not changed in many axonal tracts and terminals in the $C h p 1^{\mathrm{vac} / \mathrm{vac}}$ brain, particularly in the adult, suggests that other CHP proteins may compensate for the loss of CHP1 in these neurons. In agreement, in situ analysis (www.brain-map.org) showed that both $C h p 1$ and $C h p 3$ transcripts were expressed in cerebellar granule cells, whereas only Chp1 was expressed in Purkinje cells (Lein et al., 2007). Moreover, we found temporal differences in the protein levels of CHP3 and CHP1 in the mouse cerebellum. Although CHP1 levels remained constant from the early postnatal to the adult cerebellum, CHP3 levels were very low at P7 but steadily increased during the course of cerebellar development. Therefore, CHP1 is likely necessary for the cell surface expression of NHEs during early postnatal development, whereas CHP3 may compensate for the loss of CHP1 in a subset of neurons in the adult brain. This compensation may explain the absence of some of the nonPurkinje cell phenotypes in Chp1-deficient mice (e.g., DCN degeneration and seizures) that were observed in $\mathrm{Nhe}^{\text {swe/swe }}$ mice (Cox et al., 1997). Alternatively, phenotypic differences between these mutant strains could be due to low levels of the $\mathrm{CHP}^{\mathrm{D} 168 \mathrm{G}}$ isoform that may promote maturation of a limited amount of NHE1, which, in some neurons, could be sufficient for their survival and/or function.

Although we have shown here that disruption of NHE1 function causes Purkinje cell axon degeneration, the mechanism by which NHE1 causes axonal defects remains unclear. Recent in vitro studies have implicated an important role for NHE1 in early neurite morphogenesis of PC12 neuroendocrine cells and murine neocortical neurons (Sin et al., 2009). Similarly, NHE5 has been shown to be actively recruited to dendritic spines and to be involved in local $\mathrm{pH}$ regulation that affects spine growth (Diering et al., 2011). Other studies suggest that NHE1 function and $\mathrm{pH}$ regulation are important in the modulation of synaptic activity, which in turn may affect axon homeostasis (Dietrich and Morad, 2010). In addition to synaptic dysfunction, NHE1 deficiency may cause misregulation of other ions such as calcium due to the functional coupling of ion pumps and exchangers at the synapse. Indeed, it has been shown that the perturbations in intracellular calcium and sodium homeostasis via functional coupling of NHE1 and NCX1 play key roles in ischemic cell death of the heart (Hilgemann et al., 2006). Not surprisingly, we observed localization of NCX1 at presynaptic terminals of Purkinje cells in the P8 wild-type cerebellum, suggesting that active regulation of $\mathrm{Ca}^{2+}$ homeostasis occurs during the maturation of the presynaptic terminals of Purkinje cells (Y.L. and S.L.A., unpublished observations). Although more research is needed to elucidate the mechanisms by which NHE1 deficiency initiates axon degeneration, our results demonstrate the importance of this exchanger for axon integrity.

\section{References}

Aharonovitz O, Zaun HC, Balla T, York JD, Orlowski J, Grinstein S (2000) Intracellular $\mathrm{pH}$ regulation by $\mathrm{Na}(+) / \mathrm{H}(+)$ exchange requires phosphatidylinositol 4,5-bisphosphate. J Cell Biol 150:213-224. CrossRef Medline

Barmack NH, Qian Z, Yoshimura J (2000) Regional and cellular distribution of protein kinase $\mathrm{C}$ in rat cerebellar purkinje cells. J Comp Neurol 427:235-254. CrossRef Medline

Barroso MR, Bernd KK, DeWitt ND, Chang A, Mills K, Sztul ES (1996) A novel $\mathrm{Ca}^{2+}$-binding protein, $\mathrm{p} 22$, is required for constitutive membrane traffic. J Biol Chem 271:10183-10187. CrossRef Medline

Baumgartner M, Patel H, Barber DL (2004) $\mathrm{Na}(+) / \mathrm{H}(+)$ exchanger NHE1 as plasma membrane scaffold in the assembly of signaling complexes. Am J Physiol Cell Physiol 287:C844-C850. CrossRef Medline

Bechtold LS (2000) Ultrastructural evaluation of mouse mutations. in: sys- tematic approach to evaluation of mouse mutations (Sundberg JP, Boggess D, eds). Boca Raton, FL: CRC.

Bell SM, Schreiner CM, Schultheis PJ, Miller ML, Evans RL, Vorhees CV, Shull GE, Scott WJ (1999) Targeted disruption of the murine Nhe1 locus induces ataxia, growth retardation, and seizures. Am J Physiol 276: C788-C795. Medline

Brett CL, Donowitz M, Rao R (2005) Evolutionary origins of eukaryotic sodium/proton exchangers. Am J Physiol Cell Physiol 288:C223-C239. CrossRef Medline

Casey JR, Grinstein S, Orlowski J (2010) Sensors and regulators of intracellular pH. Nat Rev Mol Cell Biol 11:50-61. CrossRef Medline

Chesler M (2003) Regulation and modulation of $\mathrm{pH}$ in the brain. Physiol Rev 83:1183-1221. CrossRef Medline

Coleman M (2005) Axon degeneration mechanisms: commonality amid diversity. Nat Rev Neurosci 6:889-898. CrossRef Medline

Cox GA, Lutz CM, Yang CL, Biemesderfer D, Bronson RT, Fu A, Aronson PS, Noebels JL, Frankel WN (1997) Sodium/hydrogen exchanger gene defect in slow-wave epilepsy mutant mice. Cell 91:139-148. CrossRef Medline

Diering GH, Mills F, Bamji SX, Numata M (2011) Regulation of dendritic spine growth through activity-dependent recruitment of the brain-enriched $\mathrm{Na}(+) / \mathrm{H}(+)$ exchanger NHE5. Mol Biol Cell 22: 2246-2257. CrossRef Medline

Dietrich CJ, Morad M (2010) Synaptic acidification enhances GABAA signaling. J Neurosci 30:16044-16052. CrossRef Medline

Di Sole F, Babich V, Moe OW (2009) The calcineurin homologous protein- 1 increases $\mathrm{Na}(+) / \mathrm{H}(+)$-exchanger 3 trafficking via ezrin phosphorylation. J Am Soc Nephrol 20:1776-1786. CrossRef Medline

Di Sole F, Vadnagara K, Moe OW, Babich V (2012) Calcineurin homologous protein: a multifunctional $\mathrm{Ca}^{2+}$-binding protein family. Am J Physiol Renal Physiol 303:F165-F179. CrossRef Medline

Dusart I, Sotelo C (1994) Lack of Purkinje cell loss in adult rat cerebellum following protracted axotomy: degenerative changes and regenerative attempts of the severed axons. J Comp Neurol 347:211-232. CrossRef Medline

Ferri A, Sanes JR, Coleman MP, Cunningham JM, Kato AC (2003) Inhibiting axon degeneration and synapse loss attenuates apoptosis and disease progression in a mouse model of motoneuron disease. Curr Biol 13:669673. CrossRef Medline

Gutierrez-Ford C, Levay K, Gomes AV, Perera EM, Som T, Kim YM, Benovic JL, Berkovitz GD, Slepak VZ (2003) Characterization of tescalcin, a novel EF-hand protein with a single $\mathrm{Ca}^{2+}$-binding site: metal-binding properties, localization in tissues and cells, and effect on calcineurin. Biochemistry 42:14553-14565. CrossRef Medline

Handel MA, Lessard C, Reinholdt L, Schimenti J, Eppig JJ (2006) Mutagenesis as an unbiased approach to identify novel contraceptive targets. Mol Cell Endocrinol 250:201-205. CrossRef Medline

Hilgemann DW, Yaradanakul A, Wang Y, Fuster D (2006) Molecular control of cardiac sodium homeostasis in health and disease. J Cardiovasc Electrophysiol 17:S47-S56. CrossRef Medline

Inoue $\mathrm{H}$, Nakamura $\mathrm{Y}$, Nagita $\mathrm{M}$, Takai $\mathrm{T}$, Masuda $\mathrm{M}$, Nakamura $\mathrm{N}, \mathrm{Ka}-$ nazawa $\mathrm{H}$ (2003) Calcineurin homologous protein isoform 2 (CHP2), $\mathrm{Na}+/ \mathrm{H}+$ exchangers-binding protein, is expressed in intestinal epithelium. Biol Pharm Bull 26:148-155. CrossRef Medline

Larramendi LM, Lemkey-Johnston N (1970) The distribution of recurrent Purkinje collateral synapses in the mouse cerebellar cortex: an electron microscopic study. J Comp Neurol 138:451-459. CrossRef Medline

Lein ES, Hawrylycz MJ, Ao N, Ayres M, Bensinger A, Bernard A, Boe AF, Boguski MS, Brockway KS, Byrnes EJ, Chen L, Chen L, Chen TM, Chin MC, Chong J, Crook BE, Czaplinska A, Dang CN, Datta S, Dee NR, et al. (2007) Genome-wide atlas of gene expression in the adult mouse brain. Nature 445:168-176. CrossRef Medline

Lin X, Barber DL (1996) A calcineurin homologous protein inhibits GTPasestimulated Na-H exchange. Proc Natl Acad Sci U S A 93:12631-12636. CrossRef Medline

Livak KJ, Schmittgen TD (2001) Analysis of relative gene expression data using real-time quantitative PCR and the 2(-Delta Delta $\mathrm{C}(\mathrm{T})$ ) method. Methods 25:402-408. CrossRef Medline

Ma E, Haddad GG (1997) Expression and localization of $\mathrm{Na}+/ \mathrm{H}+$ exchangers in rat central nervous system. Neuroscience 79:591-603. CrossRef Medline

Matsushita M, Tanaka H, Mitsui K, Kanazawa H (2011) Dual func- 
tional significance of calcineurin homologous protein 1 binding to $\mathrm{Na}(+) / \mathrm{H}(+)$ exchanger isoform 1. Am J Physiol Cell Physiol 301: C280-C288. CrossRef Medline

Medana IM, Esiri MM (2003) Axonal damage: a key predictor of outcome in human CNS diseases. Brain 126:515-530. CrossRef Medline

Mishima M, Wakabayashi S, Kojima C (2007) Solution structure of the cytoplasmic region of $\mathrm{Na}+/ \mathrm{H}+$ exchanger 1 complexed with essential cofactor calcineurin B homologous protein 1. J Biol Chem 282:27412751. CrossRef Medline

Pang T, Su X, Wakabayashi S, Shigekawa M (2001) Calcineurin homologous protein as an essential cofactor for $\mathrm{Na}+/ \mathrm{H}+$ exchangers. J Biol Chem 276:17367-17372. CrossRef Medline

Pang T, Wakabayashi S, Shigekawa M (2002) Expression of calcineurin B homologous protein 2 protects serum deprivation-induced cell death by serum-independent activation of $\mathrm{Na}+/ \mathrm{H}+$ exchanger. J Biol Chem 277: 43771-43777. CrossRef Medline

Pang T, Hisamitsu T, Mori H, Shigekawa M, Wakabayashi S (2004) Role of calcineurin $\mathrm{B}$ homologous protein in $\mathrm{pH}$ regulation by the $\mathrm{Na}+/ \mathrm{H}+$ exchanger 1: tightly bound $\mathrm{Ca}^{2+}$ ions as important structural elements. Biochemistry 43:3628-3636. CrossRef Medline

Petzold A (2005) Neurofilament phosphoforms: surrogate markers for axonal injury, degeneration and loss. J Neurol Sci 233:183-198. CrossRef Medline
Rotin D, Grinstein S (1989) Impaired cell volume regulation in $\mathrm{Na}(+)-\mathrm{H}+$ exchange-deficient mutants. Am J Physiol 257:C1158-C1165. Medline

Sánchez-Armass S, Martínez-Zaguilán R, Martínez GM, Gillies RJ (1994) Regulation of $\mathrm{pH}$ in rat brain synaptosomes. I. Role of sodium, bicarbonate, and potassium. J Neurophysiol 71:2236-2248. Medline

Saxena S, Caroni P (2007) Mechanisms of axon degeneration: from development to disease. Prog Neurobiol 83:174-191. CrossRef Medline

Sin WC, Moniz DM, Ozog MA, Tyler JE, Numata M, Church J (2009) Regulation of early neurite morphogenesis by the $\mathrm{Na}+/ \mathrm{H}+$ exchanger NHE1. J Neurosci 29:8946-8959. CrossRef Medline

Stokin GB, Lillo C, Falzone TL, Brusch RG, Rockenstein E, Mount SL, Raman R, Davies P, Masliah E, Williams DS, Goldstein LS (2005) Axonopathy and transport deficits early in the pathogenesis of Alzheimer's disease. Science 307:1282-1288. CrossRef Medline

Stys PK (2004) White matter injury mechanisms. Curr Mol Med 4:113-130. CrossRef Medline

Waxman SG, Kocsis JD, Stys PK (1995) The axon: structure, function and pathophysiology. New York; Oxford: Oxford UP.

Zaun HC, Shrier A, Orlowski J (2008) Calcineurin B homologous protein 3 promotes the biosynthetic maturation, cell surface stability, and optimal transport of the $\mathrm{Na}+/ \mathrm{H}+$ exchanger NHE1 isoform. J Biol Chem 283: 12456-12467. CrossRef Medline 